\title{
FLUTUAÇ̃̃O POPULACIONAL E FATORES CLIMÁTICOS AFETANDO A DISTRIBUIÇÃO DE MACHOS DE Ceratitis capitata (WIED., 1824) (DIPTERA: TEPHRITIDAE) EM POMARES DE CITROS
}

\author{
ANTONIO SERGIO FERRAUDO
}

Orientador: Prof. Dr. JULIO MARCOS MELGES WALDER

\begin{abstract}
Dissertação apresentada à Escola Superior de Agricultura "Luiz de Queiroz" da Universidade de São Paulo, para obtenção do título de Mestre em Agronomia. Área de Concentração: Energia Nuclear na Agricultura.
\end{abstract}

P IR A C I C A B A

Estado de São Paulo - Brasil

Dezembro - 1987 
Aos meus

$$
\text { pais e sogros }
$$

$\bar{A} \operatorname{minha}$

$$
\text { immá e cumhados }
$$

\section{AGRADEC,O}

$\bar{A}$ minha esposa

E'Zycine

Aos meus filhos

Guizherme, Danilo e Tatiana 


\section{HOMENAGEM ESPECIAL}

Aos meus tios MARIO PILAN e DALVA FERRAUDO PILAN, pela dedi caçao, amor e carinho em toda a minha vida.

Ao professor ARMANDO RIGHETTO, pela amizade, atençao, didá tica e incentivo quando do ingresso no ensıno superior.

Aos meus pais JOÃO e MARIA, que mesmo sem oportunidade de estudar ensinaram-me coisas, simples como andar, belas como o sorrıso, rı cas como a razão, duras como a verdade, tristes como o adeus e, dentre ou tras, divinas como a justiça. 


\section{AGRADECIMENTOS}

Ao Prof. Dr. JÚlio MARCOS MELGES WALDER, pela orientação, constante disponibilidade e amizade.

A SEÇÃO DE ENTOMOLOGTA DO CENA por ter cedido os dados para a realização deste trabalho.

Ao Prof. Dr. DILERMANDo PERECIN, pelos ensinamentos, críti cas, sugestões e constante disponibilidade.

Ao Prof. Dr. VICENTE DE PAULA PEREIRA, do Departamento de Solos e Adubos da Faculdade de Ciências Agrärias e Veterinärias, Campus de Jaboticabal, UNESP, pela elaboração do Summary.

Aos PROFESSORES DAS DISCIPLINAS CURSADAS, pelos ensinamen tos e experiências transmitidas.

Ao Prof. Dr. JOSE CARLOS BARBOSA, pela constante disponibi lidade e desenvolvimento dos programas para as anälises gräficas e estatís ticas .

À CAPES, em nome do Programa Institucional de Capacitação de Docentes da Faculdade de Ciências Agrärias e Veterinárias, Campus de Jabo ticaba1, UNESP, e à FUNDAÇÃO "JUDITH BUZAID", pelo auxĩ1io financeiro pres tado.

Ao Prof. Dr. RICARDO B. SGRILLO, pela atenção, amizade e sü gestões anteriores a este trabalho.

Aos COLEgAS do Departamento de Ciências Exatas da Faculdade de Ciências Agrárias e Veterinárias, Campus de Jaboticabal, UNESP, pelo in. centivo e colaboração.

Aos FUNCIONÁRIOS da Unidade de Processamento de Dados da Fa culdade de Ciências Agrärias e Veterinärias, Campus de Jaboticabal, UNESP.

$\bar{A}$ Sra. ANA SILVIA PAMPLONA MARIANo, pela correção na Litera tura Citada. 
A Srta. MARIA JOSE SERVIDONE, pelo trabalho de datilografia realizados com presteza.

$\bar{A}$ TODO AQUELE que, direta ou indiretamente, colaboraram pa ra a realização deste trabalho.

$\bar{A}$ DEUS, por ter me concedido a vida. 


\section{I $N$ D I C E}

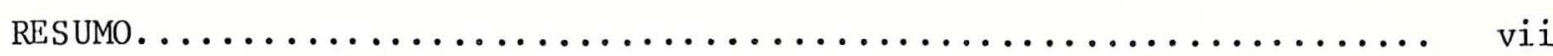

SUMMARY $\ldots \ldots \ldots \ldots \ldots \ldots \ldots \ldots \ldots \ldots \ldots \ldots \ldots \ldots \ldots \ldots \ldots \ldots \ldots \ldots \ldots \ldots \ldots \ldots \ldots$

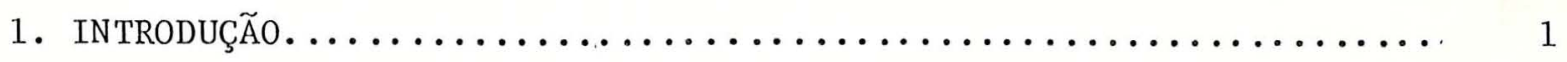

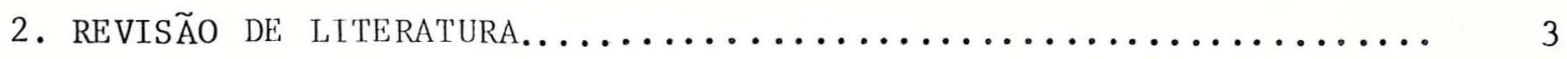

2.1. A Técnica do Macho (ou Inseto) Estéril................ 3

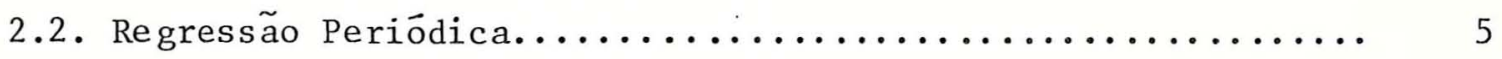

2.3. Distribuição Espacial de Insetos................... 6

2.4. Correlações com Dados Climáticos................. 8

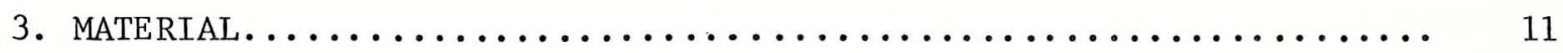

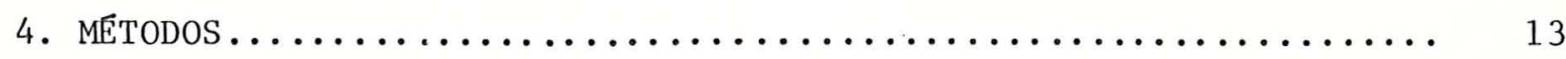

4.1. Anālises de Regressão Earmōnica individuais............. 13

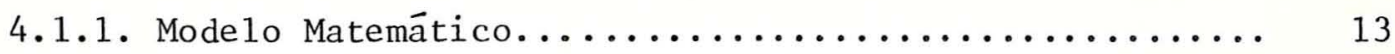

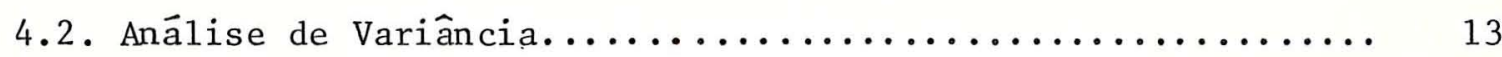

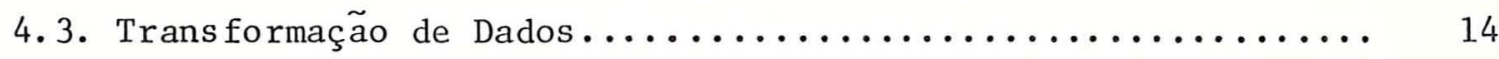

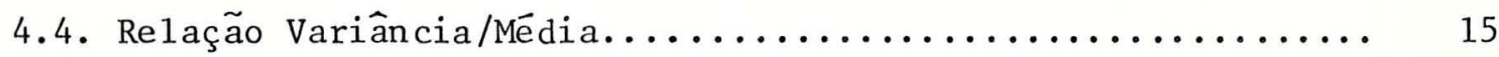

4.5. Correlação com Dados Climáticos................. 16

4.6. Anālises Estatísticas ......................... 16

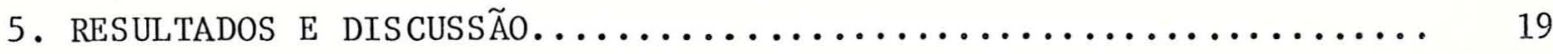

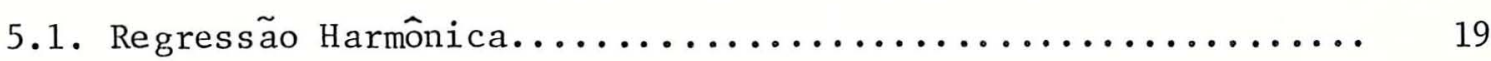

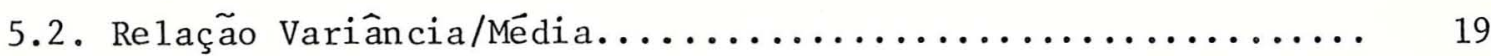

5.3. Correlação com Dados C1imáticos................. 42

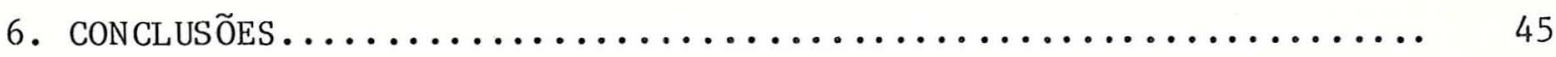

7. LITERATURA CITADA.......................... 46

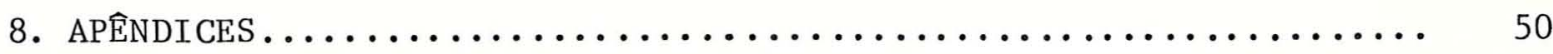


vii.

\title{
FLUTUAÇÃO POPULACIONAL E FATORES CLIMÁTICOS AFETANDO A DISTRIBUICÃ̃C DE MACHOS DE ceratitis capitata (WIED., 1824) (DIPTERA: TEPHRITIDAE) EM POMARES DE CITROS
}

\author{
Autor: ANTONIO SERGIO FERRAUDO \\ Orientador: Prof. Dr. JULIO MARCOS MELGES WALDER
}

\section{RE SUMO}

No presente trabalho procurou-se determinar um modelo mate mático que possa representar, pelo menos aproximadamente, a evolução da mosca-do-mediterrâneo, Ceratitis capitata (Wied., 1824) (Diptera: Tephriti dae) em dois pomares situados no município de São Pedro (SP).

Os dados, número de machos coletados, foram obtidos de experimentos realizados durante quatro anos (janeiro de 1980 a dezembro de 1983).

Em cada um dos pomares distribuiram-se armadilhas que cole taram os insetos machos da mosca e, com os dados obtidos, estudaram-se re gressões harmônicas para cada variedade e ano, de acordo com metodologia descrita por BLISS (1970), com as respectivas anālises de variância.

Com a exceção da variedade Pêra, que no primeiro ano apre sentou resultados näo significativos, as anālises mostraram que nos dois primeiros anos, onde a densidade populacional da praga foi alta, todas as regressões harmônicas foram significativas, sendo que quatro resultaram em ajuste ao modelo do primeiro grau, duas do segundo, sete do terceiro e qua tro do quarto grau. Nos dois anos finais a praga praticamente desapareceu dos pomares apresentando baixa densidade populacional, o que resultou em anālises com resultados não significativos.

Foi realizado também um estudo da relação variância/média, como uma medida de aproximação à distribuição espacial da praga, assim co mo as possíveis correlações de dados climáticos, para verificar possíveis interferências na evolução da praga. 


\section{POPULATION DINAMICS AND CLIMATIC FACTORS AFFECTING THE Ceratitis capitata (WIED., 1824)(Diptera: Tephritidae) MALE DISTRIBUTIONS ON CITRIC ORCHARDS}

Author: ANTONIO SERGIO FERRAUDO

Adviser: Prof. Dr. JULIO MARCOS MELGES WALDER

\section{SUMMARY}

In the present work it was looked for determining a mathe tical model to represent, at least nearly, the mediterranean fly Ceratitis capitata (Wied., 1824) (Diptera: Tephritidae) in two citric orchards in são Pedro (SP). The experimental data, the number of males, were obtained in experiments during four yearsfrom january 1980 to december 1983.

Some traps were installed in each orchard" to catch the medi terranean fly males. After counting the number of males in the traps the harmonic regression for each year and variety was studied according to the methodology described by BLISS (1970), with the respective variance a nalyses.

Excluding the variety "Pêra", which in the first year pre sented no significant results, the analyses showed that in the two first years, where the populational density was high, all the harmonic regressions were significant. Four among them fitted to the first grade mode1, two to the second grade, seven to the third and four to the fourth grade. In the two last years the pest was gone from the orchards, the populational densi ty was low and the regression analysis was not significant.

It was also realized a study of the mean/variance relation ship as a measure of the approximation of the spatial distribution of the pest, as well as the possible correlations of climatic data for verifying the possible interferences in the pest evolution. 


\section{INTRODUÇÃO}

A Técnica do Macho Estëril (T.M.E) é um método de controle de insetos praga que apresenta certas vantagens em comparação a outros, pois não deixa resíduos, é absolutamente específico ej se aplicado continua mente pode levar a extinção total da população tratada. A técnica consis te em criar, esterilizar e soltar machos em nümero suficiente para exceder a população natural dos machos. Os machos estéreis então competem com os machos selvagens e, sob condições apropriadas, a maior parte das fêmeas ovo positará ovos estéreis, diminuindo a população natural dos insetos.

A T.M.E. é bastante complexa e exige um grande nümero de pes quisas preliminares e complementares para que se torne eficiente.

Com a intenção de se aplicar esta técnica no Brasil, pesqui sadores da Seção de Entomologia do CENA, Piracicaba - SP, iniciaram um ex perimento em São Pedro - SP, onde haviam dois pomares cítricos contendo co mo praga principal a C. capitata (Diptera: Tephritidae) tambëm conhecida como mosca-do-mediterrâneo, pois é originäria dos países do Mediterrâneo. Os resultados preliminares se encontram em Walder (1983). Segundo GALLO et alii (1970) é uma praga de clima tropical e sub-tropical, sendo notada pe la primeira vez no Brasil em 1905. Atualmente se acha difundida por todo o território, atacando os hospedeiros: pêssego, café (cereja), laranja, pê ra, abacate, goiaba e muitos outros. Esta praga produz danos de grande proporção não só à citricultura como em outros pomares. As larvas podem destruir totalmente a polpa dos frutos, tornando-os imprestäveis ao cons mo. As laranjas, desde que se aproximem da maturação, vão sendo atacadas pelas moscas, provocando a sua queda prematura.

Uma das pesquisas preliminares para a aplicação da T.M.E. é a determinação de um modelo matemático que explique a evolução da praga no 
campo. Pretende-se neste trabalho a partir de experimentos montados São Pedro, utilizando análise harmônica, determinar para cada variedade em cada um dos pomares, uma função que possa representar pelo menos, aproxima damente, a incidência da mosca-do-mediterrâneo, com a finalidade de, atra vés da T.M.E. efetuar futuramente o seu controle ou até a erradicação to ta1. 


\section{REVISÃO DE LITERATURA}

\subsection{A Técnica do Macho (ou Inseto) Estéril}

A "Técnica do Macho (ou Inseto) Estēri1" foi proposta em 1937 por E.F. Knipling, quando investigava a mosca varejeira, Cochliomyia hominivorax (coq.), uma das principais pragas do gado nos Estados Unidos. Em 1954 após vārias tentativas e muitos anos de pesquisa, conseguiu-se a erradicação dessa mosca da ilha de Curaçao e, em 1958/1959 do Sudeste dos E.E.U.U.

Segundo MELLADO (1971), vem se desenvolvendo, desde 1965, na Espanha, um programa de controle da mosca-do-mediterrâneo, atravēs da Técnica do Inseto Estëril (T.I.E.). No período de 1966 a 1968 iniciaramse na Ilha de Tenerife, ensaios de liberação de moscas estēreis não obten do sucesso durante esse período, devido em parte, ao pequeno número de in setos liberados. Cerca de 25 milhões de moscas estéreis foram liberadas ém 1968, reduzindo a infestação nessas äreas em 55\% comparadas com as äreas-testes. Em 1969, os ensaios de campo foram feitos em uma planta ção regular de citros e damasco, na província de Murcia. Aproximadamente 32 milhões de insetos foram soltos no período de março a agosto, numa su perfície de 25 ha. Neste ano conseguiu-se manter o ataque da praga infe rior a $1 \%$, enquanto que nas äreas-testes adjacentes o indice de infestação era de $60 \%$.

Segundo LABRECQUE (1982), a Agência Internacional de Ener gia Atômica (AIEA) tem dado assistência aos seguintes projetos de erradica ção ou controle de C. capitata, com o uso da T.I.E.:

$1965 / 1967$ - Projeto de controle (T.I.E.) da mosca-do-mediterrâneo, inicią do na América Centra1 (Costa Rica, Panamá, Ni carágua). 
1967 - Experimento para erradicação da mosca-do-mediterrâneo (T.I.E.), em Capri.

1968/1969 - Estudo piloto para erradicação (T.I.E.) na Tunísia.

$1969 / 1970$ - Controle (T.I.E.) em experimentos de campo, na Espanha.

$1970 / 1973$ - Estudo (T.I.E.) em Cyprus (interrompido devido a conflitos po 1iticos).

$1972 / 1973$ - Estudo de controle (T.I.E.) em Israe1.

1975 - Programa de erradicação no México (T.I.E.).

$\mathrm{Na} N$ icarägua, populações de C. capitata foram controladas através da T.M.E. (RHODE et alii, 1971) numa ärea de $48 \mathrm{~km}^{2}$ de plantações de café e citros. Houve uma redução de $91 \%$ dessa população nas äreas de liberação em relação às áreas-testes.

Em Israel muitos experimentos aplicando a Técnica do Inseto Estéril (T.I.E.), têm sido desenvolvidos a partir de 1973 (KAMBURov etalii, 1975). Os resultados mostram grande chance de sucesso desta tëcnica, principalmente quando usada em grandes äreas.

SGRILLO et alii (1974) discutem como método de controle a1 ternativo a Técnica do Macho Estéril. Esta tëcnica tem sido aplicada para controle e erradicação de algumas espécies de insetos e, pesquisas futuras poderão possibilitar sua aplicação no controle ou erradicação de outros in setos. Comentam que, teoricamente, a tẻcnica ê aplicável a qualquer espê cie que se reproduza sexualmente, desde insetos praga a ratos e outros ani mais prejudiciais à economia humana.

PATTON (1982) e LABRECQUE (1982) citam que, a mosca-do-medi terrâneo foi detectada no México, pela primeira vez, en 1977. Com o apoio da Agência Internacional de Energia Atômica (AIEA), Food and Agriculture Organization (FAO) e o Departamento de Agricultura dos Estados Unidos, cri ou-se nesse mesmo ano um programa de combate a esta praga, incluindo vá rias medidas imediatas de controle. Depois de um ano e meio, graças à in tegração do método usando inseticida com atraente e as 1iberações de inse tos estéreis, conseguiu-se a erradicação da praga em 3,1 milhões de hecta res.

Segundo KNIPLING (1982) a erradicação da mosca varejeira $C$. hominivorax é tida ainda como modelo de controle de pragas envolvendo a 1 i beração de insetos estéreis. 
IAEA (1987) informa que uma campanha a longo prazo para er radicar a mosca-do-mediterrâneo está sendo conduzida no Sul do Japão com ajuda financeira dos ministërios da agricultura, florestal e pesca. Esta campanha iniciou-se na Itha de Miyako em setembro de 1984 para proteger as colheitas de melão, da praga. Apōs dois anos de extensivos esforços, as moscas foram quase eliminadas. Espera-se que até 1992 ocorra a erradica ção total da mosca-do-mediterrâneo em plantações de melão no Japão.

Segundo LINDQUIST (1987), atualmente a T.I.E. estä sendo aplí cada em 10 espécies de insetos praga. Estão sendo conduzidas pesquisas em outras espécies, esperando-se que essa tecnologia seja mais amplamente usa da no futuro. Ela é aplicada em grandes äreas para erradicação, quarente na e controle devido principalmente ao alto custo total do programa que en volve esta tëcnica. Deve-se usä-la também quando tentativas com outras técnicas que usam inseticidas jā foram aplicadas sem sucesso, tornando os insetos resistentes, acarretando um aumento na população.

\subsection{Regressão Periödica}

Regressão periỏdica è uma curva que relaciona uma variável em função, no geral, do tempo e é repetida em intervalos fixos. E conheci da em textos de matemätica como uma "Curva de Fourier" e è ütil para qual quer espécie de dados que tende a flutuar sobre intervalos regulares. E muito ütil para muitas espécies de dados de agricultura.

A equação geral para uma curva periödica é:

$$
\begin{aligned}
Y= & a_{0}+a_{1} \cos (C X)+b_{1} \operatorname{sen}(C X)+a_{2} \cos (2 C X)+b_{2} \operatorname{sen}(2 C X)+ \\
& +a_{3} \cos (3 C X)+b_{3} \operatorname{sen}(3 C X)+\ldots
\end{aligned}
$$

onde X é uma observação de tempo e C é uma constante igual a 360 o dividido pelo número de intervalos do ciclo considerado (LITTLE \& HLLLS, 1975).

BLISS (1958) apresentou um trabalho sobre regressão harmôni ca aplicada à Biologia e Climatologia, no qual justifica o método. Cita que muitas vezes os dados não se adaptam a uma regressão polinomial, por pos suírem tendências claramente periódicas. Mostra como obter os coeficien tes de regressão e a anâlise de variância para testes estatísticos. 
Panofsky \& Brier em 1958, citados por DUARTE (1981), mostram que qualquer curva pode ser representada como a soma de uma sërie de dife rentes curvas do seno; assim è que doze valores mensais podem ser adequada mente representados por seis curvas do seno. A curva com freqüeñcia 1, isto $\vec{e}$, com um mäximo e um mỉnimo é a $1^{\underline{a}}$ harmônica; ela descreve a variação anu

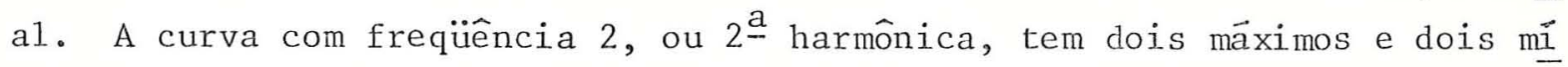
nimos e descreve a variação semestral e assim sucessivamente.

BLISS (1970) em seu livro apresenta um capitulo dedicado à anälise periódica, relacionando sua importância e descrevendo os métodos para estimativas dos parâmetros e anālise de variância.

THIËBAUT (1976), usando análise harmônica no estudo das pre cipitações pluviométricas mensais do município de Viçosa (MG), observou que para os períodos chuvosos e secos, a onda semestral foi responsável por, no mínimo, $82 \%$ da variação devida a meses enquanto a onda anual foi responsâ vel por $95,02 \%$ dessa variação.

FELTRIN (1980) estudou as precipitações pluviais através da regressão harmômica no município de Bandeirantes (PR). Observou dois pe ríodos: um seco (de abril a setembro) e outro chuvoso (de outubro a narço). Estimou modelos para esses dois períodos bem como as precipitações pluvio métricas mäximas e mínimas.

DUARTE (1981) realizou um trabalho com o objetivo de deter minar uma equação para representar matematicamente a incidência da ferrugem alaranjada Hemileia vastatmix Berk et Br do cafeeiro no Estado de Minas Ge rais e concluiu que o primeiro componente harmônico è o principal responsä vel pela variação mensal na incidência de ferrugem do cafeeiro.

TAYLOR (1986) usou para ajustes a anālise de regressão pe riódica por verificar variação cíclica no nümero de lepidópteros captura dos em armadilhas luminosas a leste da África.

\subsection{Distribuição Espacial de Insetos}

EVANS (1953) observou que contagens de insetos se ajustam bem à distribuição binomial enquanto que contagens de plantas, em quadra dos, ajustam-se bem à distribuição de Neyman Tipo A, atribuindo a diferen ça à competição e abarrotamento no caso de plantas. 
Mcguire e seus colaboradores, em 1957, citados por BARBOSA (1985), sugerem que a inflação da variância de uma distribuição de Poisson pode levar a um modelo espacial do tipo agrupado. Muitas vezes, os orga nismos são depositados aleatoriamente; porēm, devido ao movimento dentro da população, os mesmos vão formando agrupamentos.

Embora existam värias distribuições que podem ser ajustadas a dados de contagens de insetos, segundo um grande número de pesquisadores, a distribuição binomial negativa caracteriza melhor as espécies de insetos, que formam agrupamentos, do que qualquer outro modelo estudado (WATERS \& HENSON, 1959; SEVACHERIAN \& STERN, 1972; PIETERS \& STERLING, 1973; SHEPARD, 1972).

PIELOU (1977) cita que uma propriedacle das distribuições discretas de contágio é que a variância exceda a média, enquanto para a dis tribuição de Poisson a variância e a mëdia são iguais. Sugere então o uso da razão variância/média $(\mathrm{V} / \mathrm{m})$ como uma medida de agregação. 0 autor cita ainda que David \& Moore em 1954, sugeriram, como uma medida de agregação, $I=(V / m)-1$, chamado de índice de agregação, e descrevem um método para comparar dois valores de $I$, digamos $I_{1}$ e $I_{2}$ de duas populações diferentes. PERECIN (1978) mostrou que, entre outras, distribuições de adultos de lepidópteros praga em fases lunares ou em trimestres tendem a ajustar-se aproximadamente a distribuições binomiais com $\underline{k}$ comum.

YUEN-SHAUNG et alii (1983) estudaram a distribuição espa cial do segundo, do começo e do fim do terceiro instares das populações de larvas Popillia japonica Newman em Nova Jersey. Estes três estägios de lar vas foram melhor descritos pela distribuição binomial negativa.

QUINTEROS (1984), estudando a distribuição espacial de 1a gartas de Scrobipalpula absoluta (Mey., 1917) (Lep.-Gelechriidae) em cu1tü ra de tomate, concluiu que, numa comparação entre Poisson, binomial genera 1izada, binomial negativa, Neyman Tipo A e Poisson Dupla de Thomaz, a bino mial negativa descreveu melhor a distribuição espacial da praga, sendo esta equivalente à binomial generalizada.

BARBOSA (1985), estudando a broca da cana Diatraea sacchar $\underline{a}$. Zis (Fabr., 1794), comenta que a determinação de uma distribuição de proba bilidade que possa descrever a distribuição espacial de cada praga em cada cultura é de fundamental importância para o estabelecimento de critérios 
adequados de amostragem, análises estatísticas e decisão sobre o controle da praga. Fez um estudo sobre ajuste de dados às distribuições de Poisson, binomiais negativas e de Neyman Tipo A.

A lei potência de Taylor, o modelo de Iwao e a distribuição binomial negativa com k comum são usadas, segundo ELLIOT \& KIECKHEFER (1987), para relacionar variância e média de populações. A lei potência de Taylor geralmente fornece um melhor ajuste para relacionar variância e média, do que os outros dois.

NOWIERSKI et alii (1987) em estudos com Urophona affinis e Urophona quadrifasciata (Diptera: Tephritidae) verificaram um ótimo ajuste ao modelo potência de Taylor. Comparando os parâmetros $\beta_{1}$ do modelo de Taylor, observou que a dispersão espacial de Urophona affinis foi mais agre gada do que Urophona quadrifasciata.

ELLIOTT \& KIECKHEFER (1987) usaram os modelos: potência de Taylor, Iwao e binomial negativa com $k$ comum para relacionar variância e média, em populações de quatro espécies de afídeos de cereais: Schizaphis graminum (Rondani), Macrosiphum avenae (F.), Rhopalosiphum padi (L.) e Rho palosiphum maidis (Fich), em campos de aveia e trigo de inverno em Dakota do Sul. A lei potência de Taylor geralmente forneceu um melhor ajuste do que os outros dois.

Segundo SALIFU \& HODGSON (1987) as caracteristicas de dis persão no interior da planta de Megalurothrips sjastedti (Trybom) foram de terminadas em estudo de feijão na Nigéria. O modelo de regressão de Iwao e a anālise da lei potência de Taylor foram usadas para relacionar a variân cia e a média das contagens de larvas e adultos apresentando, ambas, agre gações principalmente para médias mais altas. Essas agregações foram me 1hor descritas pela distribuição binomial negativa.

\subsection{Correlações com Dados Climáticos}

PUZZI \& ORLANDO (1965) concluiram que os elementos meteoro lógicos não influenciaram na coleta das moscas (C. capitata e Anastrepha fraterculus) em pomar de citros.

SILVEIRA NETO (1969) observou a influência de fatores meteo rológicos sobre a distribuição da população da broca da figueira Azochis 
gripusalio walker durante o ano. O aumento da coleta da praga foi propor cional à elevação de temperatura, umidade relativa e precipitação pluviomé tica. Foi também inversamente proporcional à elevação da pressão baromé trica. SILVEIRA NETO (1972) observou a influência de fatores meteorológi cos sobre a distribuição da população de pragas da ordem Lepidóptera. Hou ve correlação significativa entre o nümero de mariposas coletadas e os da dos referentes a pressão barométrica, temperaturas máxima, média e mínima, umidade relativa, precipitação, insolação e vento, apresentando, no entan to, variações com relação às espécies, aos locais e aos próprios fatores meteorológicos.

ORLANDO \& SAMPAIO (1973) e SUPLICY FILHO et alii (1978) não verificaram correlação dos fatores climáticos com a captura da mosca-dasfrutas.

LARA (1974) concluiu que o número de indivíduos coletados com armadilhas luminosas, quando correlacionado com os fatores meteorológi cos registrados durante os perỉodos de coleta, apresentaram para as espé cies :

a) D. saccharalis (Fabr.), correlação negativa com a pres são baromētrica e a umidade relativa do ar;

b) Elasmopalpus Zignoselus (Zeller), correlação negativa com a pressão e temperatura média;

c) Utetheisa ornatrix (L.), correlação negativa com a tempe ratura média;

d) Heliothis zea (Bod.), nenhuma correlação.

Tambēm para as quatro espécies o nümero de indivíduos não apresentou correlação significativa com os fatores meteorolögicos registra dos duas semanas antes das coletas.

PARRA et alii (1982) estudaram a flutuação populacional (mo vimentos dispersivos e não dispersivos) e a atividade diāria de vôo de adul tos de $C$. capitata, em função dos fatores físicos do ambiente, registrados macro e microclimaticamente em cafeeiros "Mundo Novo", em Campinas e Pindo rama (SP). Concluíram que dentre os parâmetros meteorológicos, tomados ma croclimaticamente, a temperatura foi o fator que mais afetou a dinâmica po pulacional do inseto. A população, nos três espaçamentos estudados, cor relacionou-se positivamente com a temperatura e negativamente com a umida 
de relativa, quando esses dados foram tomados microclimaticamente.

VARGAS et alii (1982) estudaram a distribuição de C. capita ta na ilha de Kauai (Hawaii), usando para captura dos insetos armadilhas contendo atrativo químico (trimedlure) e verificaram que somente a precipi tação pluviomêtrica influenciou a coleta.

DUARTE et alii (1985) concluĩram que para previsão da inci dência da ferrugem do cafeeiro em um determinado mês, deve-se ter conheci mento da temperatura mínima e da precipitação cinco meses antes.

FERNANDES (1987) verificou existir correlação negativa en tre a coleta de mosca-de-frutas (total) e da mosca-do-mediterräneo, com a precipitação pluviométrica.

GAHUKAR (1987) estudou a dinâmica populacional de 23 espê cies de Atherigona no Senegal e verificou que a A. soccata (Rondani)(Dipte ra: Muscidae) foi a mais comum e numerosa. Observou correlações entre chu va, temperatura, umidade relativa e o nümero de moscas, encontrando porém a existência de interação entre esses parâmetros. A temperatura máxima re sultou em valores negativos dos coeficientes de correlação enquanto que a temperatura mínima, umidade relativa (mäxima e minima) e chuva resultaram em valores positivos. 


\section{MATERIAL,}

Os experimentos desenvolveram-se em dois pomares de citros no município de São Pedro, SP. Os pés de citros na época possuiam idade de 8 a 12 anos. Estas áreas foram escolhidas por fotografia aérea, estando re lativamente bem isoladas das demais äreas citrículas da região. A cultura ao redor dos pomares é predominantemente de cana-de-açúcar, o que valoriza o estudo pois não hả migração para outros pomares frutïferos.

As variedades cítricas plantadas foram as seguintes:

POMAR A: 1aranja Pêra Citrus sinensis Osbeck (21\%); 1aranja Valência C $i$ trus sinensis Osbeck (35\%); 1aranja Natal Citrus sinensis Osbeck (24\%); tangerina Murcote Citrus reticulata Blanco (12\%); tangeri na Ponkan Citrus reticulata Blanco (7\%) e limão Taití Citrus Lati folia Tanaka (1\%).

POMAR B: laranja Pêra Citrus sinensis Osbeck (42\%); 1imoeiro Cravo Citrus Zimonia Osbeck (20\%); 1aranja Piralima Citrus sinensis Osbeck (25\%); tangerina Murcote Citrus reticulata Blanco (13\%). As armadilhas para captura das moscas foram do tipo "NADEL", compostas do atrativo químico Trimedlure que tem a propriedade de atrair os machos da espécie, adicionado à $5 \%$ de um inseticida à base de DDVP para matar as moscas atraídas para o interior do frasco. As armadilhas foram espaçadas em 350 metros uma da outra evitando com isso interferência na captura das moscas. Tais armadilhas foram assim distribuidas: 
POMAR A

\begin{tabular}{cl}
\hline Armadilha no & Variedade \\
\hline 01 & Ponkan \\
02 & Natal \\
03 & Natal \\
04 & Nata1 \\
05 & Murcote \\
06 & Valência \\
07 & Valência \\
08 & Valência \\
09 & Pêra \\
10 & Valência \\
11 & Valência \\
12 & Pêra \\
13 & Murcote \\
14 & Pêra \\
\hline
\end{tabular}

POMAR B

\begin{tabular}{cl}
\hline Armadilha nọ & Variedade \\
\hline 15 & Pêra \\
16 & Pêra \\
17 & Pêra \\
18 & Pêra \\
19 & Piralima \\
20 & Piralima \\
21 & Cravo \\
22 & Cravo \\
23 & Murcote \\
\hline
\end{tabular}

Os períodos do ciclo de infestação, que originaram os da dos, constam da Tabela 1 .

TABELA 1 - Períodos referentes aos ciclos de infestação da praga C. copita ta.

POMAR A

POMAR B

\begin{tabular}{|c|c|c|c|c|}
\hline $09 / 06 / 80$ à $19 / 02 / 81$ & - & 19 ano & - & $10 / 07 / 80$ à $13 / 03 / 81$ \\
\hline $11 / 06 / 81$ à $18 / 02 / 82$ & - & 29 ano & - & $11 / 06 / 81$ à $01 / 04 / 82$ \\
\hline $01 / 07 / 82$ à $22 / 12 / 82$ & - & 39 ano & - & $08 / 07 / 82$ à $02 / 12 / 82$ \\
\hline $14 / 07 / 83$ à $02 / 12 / 83$ & - & 4! ano & - & $14 / 07 / 83$ à $02 / 12 / 83$ \\
\hline
\end{tabular}

Nos três primeiros anos a coleta dos insetos foi feita em média semanalmente enquanto que no quarto ano passou a ser fejta quinze nalmente interrompendo-se os experimentos em 02/12/83. Após as coletas os insetos eram levados ao laboratório para serem contados e, a partir dai, obteve-se, para cada variedade e ano, o número médio de insetos. machos (Apêndices 1 a 8 ). 


\section{METODOS}

\subsection{Análises de Regressão Harmônica Individuais}

A aplicação da análise harmônica foi feita da maneira usual conforme metodologia descrita por BLISS (1970).

\subsubsection{Modelo Matemático}

$$
E(Y)=a_{0}+\sum_{i=1}^{4}\left(a_{i} u_{i}+b_{i} v_{i}\right)
$$

onde:

$\mathrm{E}(\mathrm{Y})=$ nümero médio esperado de insetos após $\mathrm{X}$ dias do início do ciclo de evolução da praga.

$\mathrm{a}_{\mathrm{O}}=$ média dos insetos no ciclo considerado.

$\mathrm{a}_{\mathbf{i}} \mathrm{u}_{\mathbf{i}}+\mathrm{b}_{\mathrm{i}} \mathrm{v}_{\mathbf{i}}=$ componente harmônico de grau $\mathrm{i}$, onde $\mathrm{i}=1,2,3,4$.

$u_{i}=\cos (i x)$.

$v_{i}=\operatorname{sen}(i x)$.

Para a estimação dos parâmetros $a_{0}, a_{i}$ e $b_{i}$ onde $i=1,2,3$, 4, usou-se um método iterativo, cujo programa desenvo1vido por BoRATrO (1984) estima os parâmetros que minimizam o resíduo (ou desvio do modelo).

\subsection{Análise de Variância}

A partir dos modelos ajustados foram feitas as respectivas anālises de variância para cada variedade e ano.

O critērio usado foi o seguinte:

Tomaram-se o modelo estimado para o primeiro grau; determi 
nou-se as somas de quadrados dos desvios e, por diferença, utilizou-se da so ma de quadrados total e calculou-se a soma de quadrados da regressão harmô nica de primeiro grau. 0 quociente do quadrado médio desta regressão pe1o quadrado médio do desvio, origina um valor provisório da estatística F. Se este valor resultar significativo, adiciona-se ao modelo mais um componen te harmônico e repete-se os passos anteriores até se encontrar dois valo res sucessivos da estatística F não significativo. Definiu-se como grau do modelo aquele imediatamente anterior ao não significativo.

Após escolhido o grau do modelo harmônico, cada quadrado mé dio, dividido pelo último desvio de regressão harmônica escolhido para re síduo, originou os valores finais da estatística $F$, que permitiu escolher o grau da regressão harmônica (maior grau, atë o quarto, significativo).

O esquema deste critério adotado consta da Tabela 2.

TABELA 2 - Modelo de anālise de variância.

\begin{tabular}{lccccc}
\hline Fontes de Variação & G.L. & S.Q. & Q.M. & F provisório & $F_{\text {final }}$ \\
\hline Regr. H. 19 Grau & 2 & SQRH1 & QMRH1 & QMRH1/QMDRH1 & QMRH1/E \\
Desvio Regr.H. 19 Grau & N-3 & SQDRH1 & QMDRH1 & - & - \\
\hline Ad. Regr. H. 29 Grau & 2 & SQRH2 & QMRH2 & QMRH2/QMDRH2 & QMRH2/E \\
Desvio Regr. H. 29 Grau & N-5 & SQDRH2 & QMDRH2 & - & - \\
\hline Ad. Regr. H. 39 Grau & 2 & SQRH3 & QMRH3 & QMRH3/QMDRH3 & QMRH3/E \\
Desvio Regr. H. 39 Grau & N-7 & SQDRH3 & QMDRH3 & - & - \\
\hline Ad. Regr. H. 49 Grau & 2 & SQRH4 & QMRH4 & QMRH4/QMDRH4 & QMRH4/E \\
Desvio Regr. H. 49 Grau & N-9 & SQDRH4 & QMDRH4 & - & - \\
\hline Total & N-1 & & & & \\
\hline
\end{tabular}

$\mathrm{E}=$ Quadrado médio do desvio de regressão "escolhido para resíduo".

$\mathrm{N}=$ Nọ total de observações.

\subsection{Transformação de Dados}

Tomou-se o logaritmo do número médio de machos coletados. e repetiu-se todas as regressões descritas em 4.1. com o intuito de melhorar o ajuste, o que não resultou em melhoria, aceitando-se com isso as anāi 
ses sem transformação alguma, pois resultou em um modelo de aplicação mais direta.

\subsection{Relação Variância/Média}

A relação variância/média é importante para se ter uma no ção da distribuição espacial da praga em um certo péríodo.

Estimaram-se as variâncias e as médias amostrais diārias por variedade e ano, obtendo-se para o pomar A, nos dois anos, oito amostras (qua tro variedades) e para o pomar B seis amostras (três variedades). Excluiug.e deste estudo, dados provenientes de variedades com uma só armadilha.

Três modelos para representação da relação variância/mëdia foram utilizados:

$$
\begin{array}{ll}
s^{2}=\alpha_{1} \cdot \bar{x}_{1}^{\beta_{1}} & \text { (modelo potência de Taylor) } \\
s^{2}=\alpha_{2} \cdot \bar{x}+\beta_{2} \cdot \bar{x}^{2} & \text { (modelo de Iwao) } \\
s^{2}=\bar{x}+\beta_{3} \bar{x}^{2} & \text { (binomial negativa com } k \text { comum) }
\end{array}
$$

onde $s^{2}$ e $\bar{x}$ são as variâncias e médias amostrais semanais por variedade e ano e $\alpha_{1}, \alpha_{2}, \beta_{1}, \beta_{2}$ e $\beta_{3}$ são parâmetros a serem estimados.

Para a estimação dos referidos parâmetros utilizou-se a me todologia descrita em ELLIOT \& KTECKHEFER (1987).

Para avaliação do ajuste aos modelos propostos, a estatísti ca empregada para a anā1ise residual foi (ELLIOT \& KIECKHEFER), 1987:

$$
\mathrm{T}_{\mathrm{pq}}=\frac{\sum \mathrm{e}_{\mathrm{i}}^{\mathrm{p}} \cdot \hat{\mathrm{y}}_{\mathrm{i}}^{\mathrm{q}}}{\sqrt{\left(\sum \mathrm{e}_{\mathrm{i}}^{2 \mathrm{p}}\right)\left(\sum \hat{y}_{i}^{2 \mathrm{q}}\right)}}
$$

onde $\mathrm{p}, \mathrm{q}=1,2 ; \mathrm{i}=1, \ldots ., \mathrm{n} ; \hat{\mathrm{y}}_{i}$ e $\mathrm{e}_{\mathrm{i}}$ são os valores estimados e resi duais respectivamente, associados com a i-ésima observação.

Dependendo dos valores de "p" e "q", a estatística T $\mathrm{pq}$ dá uma evidência das várias inconsistências nos modelos residuais, tais como: 
a) Se $\mathrm{p}=\mathrm{q}=1$ valores a1 to de $\mathrm{T}_{11}$ dá evidência de uma ten dência linear no modelo residua1;

b) Se $\mathrm{p}=1$ e $\mathrm{q}=2$ valores alto de $\mathrm{T}_{12}$ dá a evidência da prẹ sença de curvatura no modelo residual e,

c) Se $\mathrm{p}=2$ e $\mathrm{q}=1$ valores alto de $\mathrm{T}_{21}$ da evidência da falta de homogeneidade na variância no modelo residual.

\subsection{Correlação com Dados Climáticos}

E de fundamental importância para se compreender a evolução de uma praga no campo, investigar se os fatores meteorológicos apresentam alguma influência.

Um dos métodos usados na estatística para mostrar o relacio namento linear entre duas variäveis é conhecido como "Regressão Linear Sim ples" que associa os dados observados a uma reta. o coeficiente de correla ção linear é uma medida dessa associação.

Para isso, os dados representativos do número médio de ma chos coletados foram transformados em valores mensais (Tabelas 3 e 4) e a seguir encontraram-se os valores dos coeficientes de correlação linear sim ples entre esses dados e aqueles representativos das médias mensais de tem peraturas máxima e mínima, variação de temperatura, precipitação pluviomé trica e umidade relativa.

\subsection{Anālises Estatísticas}

$\Lambda$ s anảlises estatísticas foram realizadas na Unidade de Pro cessamento de Dados da Faculdade de Ciências Agrärias e Veterinárias, UNESP, Jaboticabal - SP, através de programas especialmente desenvolvidos pelo Prof. Dr. José Carlos Barbosa do Departamento de Ciências Exatas da FCAVJ/ UNESP). 
TABELA 3 - Número médio de machos coletados em cada variedade no pomar A e fatores climáticos (Dados men sais) - período de dezembro/81 a agosto/83.

\begin{tabular}{|c|c|c|c|c|c|c|c|c|c|c|}
\hline \multirow{2}{*}{ Período } & \multicolumn{5}{|c|}{ Variedade } & \multirow{2}{*}{$\begin{array}{l}\text { Temp. máx. } \\
\text { média/mês } \\
\left({ }^{\circ} \mathrm{C}\right)\end{array}$} & \multirow{2}{*}{$\begin{array}{c}\text { Temp : miñ } \\
\text { média/mês } \\
\left({ }^{\circ} \mathrm{C}\right)\end{array}$} & \multirow{2}{*}{$\begin{array}{l}\text { Variação } \\
\text { Temp. / mês } \\
\left({ }^{\circ} \mathrm{C}\right)\end{array}$} & \multirow{2}{*}{$\begin{array}{l}\text { Precipit. } \\
\text { média/mês } \\
\qquad(\mathrm{mm})\end{array}$} & \multirow{2}{*}{$\begin{array}{c}\text { Umid. Rel } \\
\text { média/mês } \\
(\%)\end{array}$} \\
\hline & Ponkan & Natal & Murcote & Valência & Pera & & & & & \\
\hline Dez./81 & 3,0 & 20,9 & 58,0 & 40,6 & 89,5 & 29,0 & 18,4 & 10,6 & 255,7 & 85,5 \\
\hline $\operatorname{Jan} . / 82$ & 4,0 & 4,7 & 19,5 & 3,6 & 14,3 & 28,0 & 17,6 & 11,2 & 326,9 & 85,0 \\
\hline Fev./82 & 0,0 & 0,6 & 8,0 & 0,2 & 1,7 & 31,4 & 19,3 & 12,1 & 202,2 & 86,7 \\
\hline Mar./82 & 0,0 & $0 ; 0$ & 0,0 & 0,0 & 0,0 & 28,8 & 18,6 & 10,2 & 173,1 & 89,3 \\
\hline $\mathrm{Abr} / \mathrm{82}$ & 0,0 & 0,0 & 0,0 & 0,0 & 0,0 & 26,9 & 14,0 & 12,9 & 132,9 & 84,3 \\
\hline Mai./82 & 0,0 & 0,0 & 0,0 & 0,0 & 0,0 & $2.5,4$ & 10,6 & 14,8 & 63,6 & 86,9 \\
\hline Jun. / 82 & 0,0 & 0,0 & 0,0 & 0,0 & 0,0 & 25,1 & 13,5 & 11,6 & 201,7 & 90,5 \\
\hline Jul. / 82 & 2,0 & 1,6 & 2,0 & 1,4 & 1,0 & 25,8 & 11,2 & 14,6 & 28,3 & 85,9 \\
\hline Ago. $/ 82$ & 11,0 & 2,0 & 5,5 & 1,0 & 2,3 & 26,9 & 12,3 & 14,6 & 26,1 & 85,4 \\
\hline Set. $/ 82$ & 5,0 & 2,0 & 12,5 & 2,0 & 0,6 & 28,5 & 13,1 & 15,4 & 9,3 & 83,0 \\
\hline Out. $/ 82$ & 5,0 & 4,0 & 12,0 & 0,8 & 2,3 & 28,7 & 16,0 & 12,7 & 233,5 & 85,7 \\
\hline Nov, / 82 & 1,0 & 0,6 & 9,0 & 1,2 & 0,3 & 30,2 & 18,7 & 11,5 & 190,1 & 84,8 \\
\hline Dez./82 & 0,0 & 0,0 & 0,0 & 0,4 & 0,0 & 28,1 & 18,8 & 9,3 & 406,3 & 89,9 \\
\hline Fev./83 & 0,0 & 0,0 & 0,0 & 0,0 & 0,0 & 30,4 & 21,5 & 8,9 & 169,5 & 87,0 \\
\hline Mar./83 & 0,0 & 0,0 & 0,0 & 0,0 & 0,0 & 30,4 & 21,1 & 9,3 & 119,2 & 88,8 \\
\hline Abr. $/ 83$ & 0,0 & 0,0 & 0,0 & 0,0 & 0,0 & 28,7 & 19,4 & 9,3 & 152,4 & 90,9 \\
\hline Mai./83 & 0,0 & 0,0 & 0,0 & 0,0 & 0,0 & 27,1 & 18,7 & 8,4 & 247,0 & 90,6 \\
\hline Jun. $/ 83$ & $\cdot 0,0$ & 0,0 & 0,0 . & 0,0 & 0,0 & 23,9 & 15,6 & 8,3 & 202,9 & 90,9 \\
\hline Jul./83 & 62,0 & 2,0 & 3,0 & 0,2 & 0,3 & 26,6 & 15,5 & 11,1 & 20,5 & 83,6 \\
\hline Ago./83 & 12,0 & 0,7 & 2,5 & 0,8 & 0,0 & 27,2 & 13,0 & 14,2 & 0,0 & 80,1 \\
\hline
\end{tabular}


TABElA 4 - Número médio de machos coletados em cada variedade no pomar B e fatores climáticos (Dados mensais) - período de dezembro/81 a agosto/83.

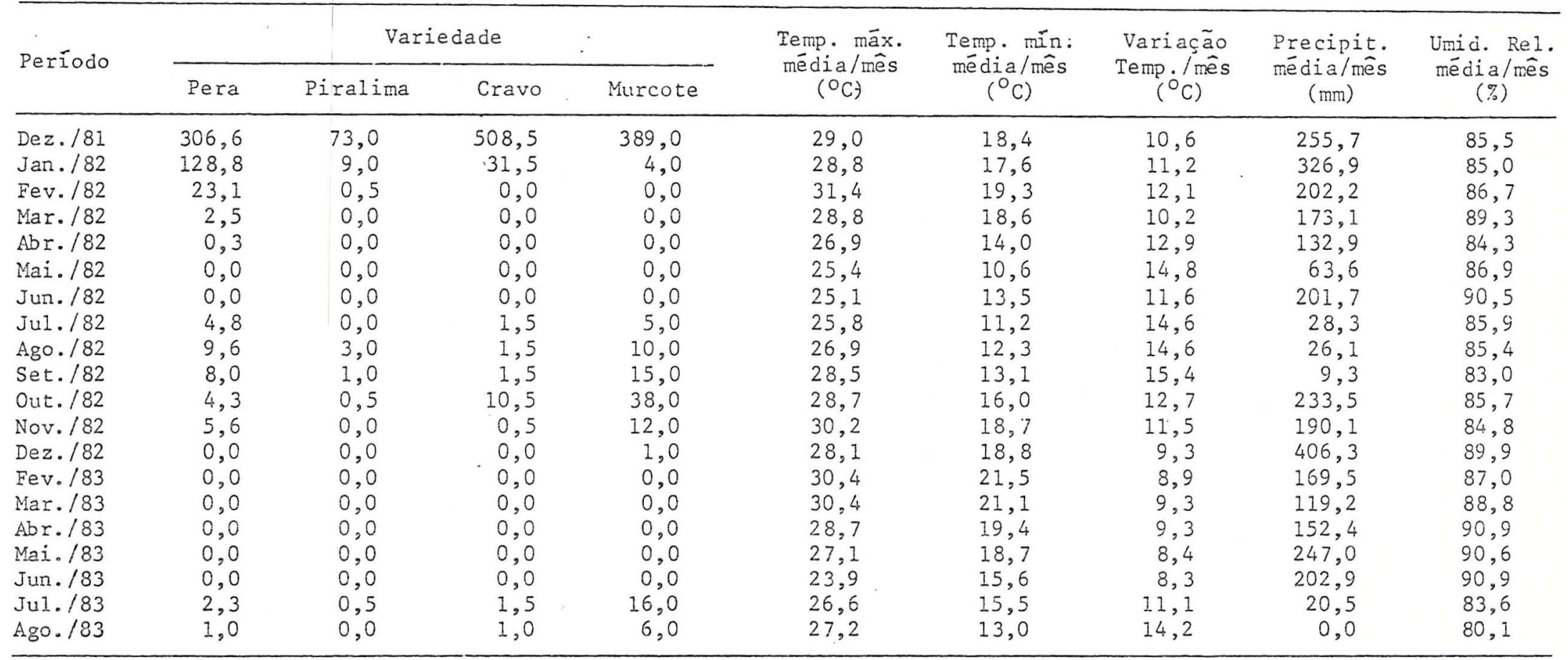




\section{RESULTADOS E DISCUSSÃO}

\subsection{Regressão Harmônica}

Das dezoito anālises de regressão harmônica feitas, apenas

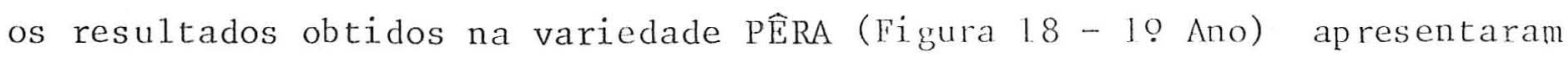
resultados não significativos durante os dois primeiros anos da incidệncia da praga (Tabelas 10 a 27 ).

Nos dois anos finais, conforme os dados mostram, a praga pra ticamente desapareceu dos pomares o que resultou em análises com resulta dos não significativos, principalmente pelos valores muito baixos dos graus de liberdade nas respectivas análises de variância.

0 ajuste dos dados ao modelo de regressão harmônica pode ser considerado razoável (Figuras 1 a 18 e Tabelas 10 a 27 de anälise de variância). Em quatro deles o primeiro componente harmônico foi significativo; em dois o primeiro e o segundo foram significativos; em sete o primeiro, segundo e terceiro foram significativos, cm quatro o primeiro, segundo, terceiro e quarto foram significativos e apenas um não significativo.

As Tabelas 5 e 6, apresentam os valores máximos observados e os estimados pelas equações ajustadas, mostrando coerência entre os valo res observados e os estimados pelo modelo harmônico.

\subsection{Relação Variâncía/Média}

E importante do ponto de vista prático determinar, quando existente, a relação variância/mëdia.

Frequentemente, variância e mëdia se relacionam através de a1guma lei e as distribuições de probabilidade podem definir essas leis. Dois exemplos ilustram isso. Se $\mathrm{s}^{2}$ e $\overline{\mathrm{x}}$ representam respectivamente a vari 
ância e a média amostrais então:

a) se $s^{2} \cong \bar{x}$, as amostras podem ser provenientes de popula ções com distribuição de Poisson (pois $\sigma^{2}=\mu$, na popula ção) ;

b) se $s^{2} \cong \bar{x}+\frac{\vec{x}^{2}}{k}$, as amostras podem ser provenientes de populações com distribuição binomial negativa, com mé dia $\overline{\mathrm{x}}$ e parämetro $\mathrm{k}$ (comum).

Baseado nessas leis, critérios surgiram para se determinar a relação variância/média e a seguir inferir as respectivas distribuições de probabilidades. Os modelos descritos em 4.4 possuem essa finalidade.

Se o ajuste ao modelo potência de Taylor $\left(s^{2} \cong \alpha_{1} \cdot \overline{\mathrm{x}}^{\beta_{1}}\right)$ apre sentar resultado significativo, e ainda

a) $\alpha_{1}=1$ e $\beta_{1}=1$, as amostras podem ser provenientes de populações com distribuições de Poisson;

b) $\beta_{1}<1$, as amostras podem ser provenientes de populações com distribuições binomiais ou distribuições uniforme, e

c) $\beta_{1}>1$, as amostras podem ser provenientes de populações com distribuições de contágio (agregada), por exemplo, a distribuição binomial negativa.

Em vista do exposto foram feitos ajustes aos modelos descri

tos em 4.4 .

Os resultados encontram-se nas Tabelas 7, 8 e 9 e mostram (quanto à análise residual) um razoável ajuste à distribuição binomial ne gativa, mas com $\mathrm{k}$ variando por semana e variedade. Os valores de $\mathrm{T}_{11}$ fo ram aproximadamente nulos mostrando não tendência linear nos resíduos do modelo ajustado. Os valores de $\beta_{3}$ variaram de 0,08 à 2,13.

De modo global, analisando os valores da estatística $\mathrm{T}_{\mathrm{pq}} \mathrm{e}$ os coeficientes de determinação $\left(r^{2}\right)$, os modelos de twao é binomial negati. va com $k$ comum são superiores ao modelo de 'l'aylor. Destes, embora não su perior ao modelo de Iwao, o modelo binomial negativa com $k$ comum pode ser o preferido por ter um só parâmetro, embora esse parâmetro possua variação semanal com as variedades, o que talvez possa ser indício de que a probabi lidade de captura não é a mesma em todas as armadilhas variando semanalmen te de acordo com a variedade. 
TABELA 5 - Valores observados e estimados das posições dos picos populacio nais da C. capitata a partir da $1^{\stackrel{a}{-}}$ contagem - Pomar A.

\begin{tabular}{ccr}
\hline Variedade & $\begin{array}{c}\text { Pico populacional } \\
\text { observado }\end{array}$ & $\begin{array}{c}\text { Pico populacional } \\
\text { estimado }\end{array}$ \\
\hline 19. Ano - Murcote & 153 dias & 153 dias \\
Natal & 132 dias & 130 dias \\
Ponkan (19̣ pico) & 62 dias & 68 dias \\
Ponkan (2ọ pico) & 146 dias & 147 dias \\
Valência & 195 dias & 187 dias \\
\hline 29 Ano - Murcote & 98 dias & 105 dias \\
Natal & 77 dias 91 dias & 111 dias \\
Ponkan & 119 dias & 85 dias \\
Valência & 105 dias & 112 dias \\
Pêra &
\end{tabular}

TABELA 6 - Valores observados e estimados das posições dos picos populacio nais da $C$. capitata a partir da $1^{\underline{a}}$ contagem - Pomar B.

\begin{tabular}{ccc}
\hline Variedade & $\begin{array}{c}\text { Pico populacional } \\
\text { observado }\end{array}$ & $\begin{array}{c}\text { Pico populacional } \\
\text { estimado }\end{array}$ \\
\hline 19. Ano - Cravo (19 pico) & 36 dias & 32 dias \\
Cravo (29 pico) & 112 dias \\
Piralima & 140 dias & 129 dias \\
Murcote & 119 dias & 116 dias \\
Pêra (19 pico) & 56 dias & 65 dias \\
Pêra (29 pico) & 161 dias & 173 dias \\
\hline 29 Ano - Cravo (19 pico) & 77 dias & 79 dias \\
Cravo (29 pico) & 154 dias & 156 dias \\
Piralima (19 pico) & 98 dias & 94 dias \\
Piralima (29 pico) & 154 dias & 155 dias \\
Murcote & 168 dias & 148 dias \\
Pêra & 168 dias & 155 dias
\end{tabular}


TABELA 7 - Resultados referentes ao modelo de Taylor.

\begin{tabular}{cccccc}
\hline$\alpha_{1}$ & $\beta_{1}$ & $\mathrm{~T}_{11}$ & $\mathrm{~T}_{12}$ & $\mathrm{~T}_{21}$ & $\mathrm{r}^{2}$ \\
\hline 1,01 & 1,57 & 0,63 & 0,77 & 0,55 & 0,63 \\
1,62 & 1,51 & 0,66 & 0,82 & 0,93 & 0,33 \\
0,68 & 2,02 & 0,78 & 0,76 & 0,86 & 0,77 \\
2,61 & 1,65 & 0,10 & $-0,13$ & 0,73 & 0,43 \\
1,01 & 1,55 & 0,64 & 0,55 & 0,49 & 0,30 \\
1,09 & 1,32 & 0,51 & 0,46 & 0,50 & 0,16 \\
0,81 & 1,70 & 0,16 & 0,06 & 0,37 & 0,30 \\
0,99 & 1,62 & 0,72 & 0,85 & 0,71 & 0,21 \\
0,53 & 1,89 & 0,98 & 0,98 & 0,99 & 0,88 \\
0,65 & 1,56 & 0,70 & 0,80 & 0,63 & 0,18 \\
0,19 & 2,14 & 0,97 & 0,92 & 0,99 & 0,55 \\
1,02 & 1,55 & 0,03 & $-0,19$ & 0,42 & 0,13 \\
1,00 & 1,99 & 0,97 & 0,99 & 0,95 & 0,65 \\
1,15 & 1,96 & 0,91 & 0,83 & 0,98 & 0,88 \\
\hline
\end{tabular}

TABELA 8 - Resultados referentes ao modelo de Iwao.

\begin{tabular}{rrrrrr}
\hline \multicolumn{1}{c}{$\alpha_{2}$} & $\beta_{2}$ & $\mathrm{~T}_{11}$ & $\mathrm{~T}_{12}$ & $\mathrm{~T}_{21}$ & $\mathrm{r}^{2}$ \\
\hline$-62,07$ & 1,45 & 0,00 & $-0,07$ & 0,31 & 0,97 \\
58,88 & $-0,26$ & 0,00 & 0,28 & 0,61 & 0,47 \\
$-12,91$ & 2,57 & 0,00 & 0,10 & 0,20 & 0,99 \\
6,63 & 1,26 & 0,00 & $-0,04$ & 0,31 & 0,98 \\
$-2,57$ & 0,47 & 0,00 & 0,15 & 0,82 & 0,85 \\
$-11,49$ & 1,33 & 0,00 & 0,01 & 0,58 & 0,91 \\
10,25 & 0,23 & 0,00 & $-0,04$ & 0,41 & 0,58 \\
$-21,47$ & 0,67 & 0,00 & 0,08 & 0,45 & 0,78 \\
148,92 & $-0,06$ & 0,00 & 0,02 & 0,70 & 0,52 \\
8,14 & 0,02 & 0,00 & 0,01 & 0,49 & 0,39 \\
4,56 & 0,05 & 0,00 & 0,00 & 0,48 & 0,36 \\
$-23,33$ & 1,92 & 0,00 & 0,25 & 0,84 & 0,75 \\
2,49 & 0,43 & 0,00 & 0,00 & 0,08 & 0,99 \\
$-26,69$ & 0,63 & 0,00 & 0,21 & 0,91 & 0,68 \\
\hline
\end{tabular}


TABELA 9 - Resultados referentes ao modelo binomial negativa com $k$ comum.

\begin{tabular}{crrrr}
\hline$\beta_{3}$ & $\mathrm{~T}_{11}$ & $\mathrm{~T}_{12}$ & $\mathrm{~T}_{21}$ & $\mathrm{r}^{2}$ \\
\hline 1,30 & 0,00 & 0,00 & 0,28 & 0,97 \\
0,08 & 0,02 & $-0,19$ & 0,34 & 0,06 \\
2,13 & 0,00 & 0,22 & 0,41 & 0,99 \\
1,32 & 0,00 & $-0,07$ & 0,34 & 0,98 \\
0,35 & 0,02 & 0,08 & 0,38 & 0,31 \\
1,07 & 0,00 & 0,25 & 0,95 & 0,68 \\
0,44 & 0,00 & 0,00 & 0,07 & 0,99 \\
0,34 & 0,00 & 0,20 & 0,85 & 0,63 \\
0,40 & 0,00 & $-0,11$ & 0,35 & 0,56 \\
0,34 & $-0,01$ & 0,19 & 0,74 & 0,83 \\
1,10 & 0,00 & 0,06 & 0,58 & 0,91 \\
0,43 & 0,00 & 0,23 & 0,70 & 0,73 \\
0,32 & 0,00 & $-0,23$ & 0,64 & 0,35 \\
0,12 & 0,01 & 0,02 & 0,27 & 0,33 \\
\hline
\end{tabular}




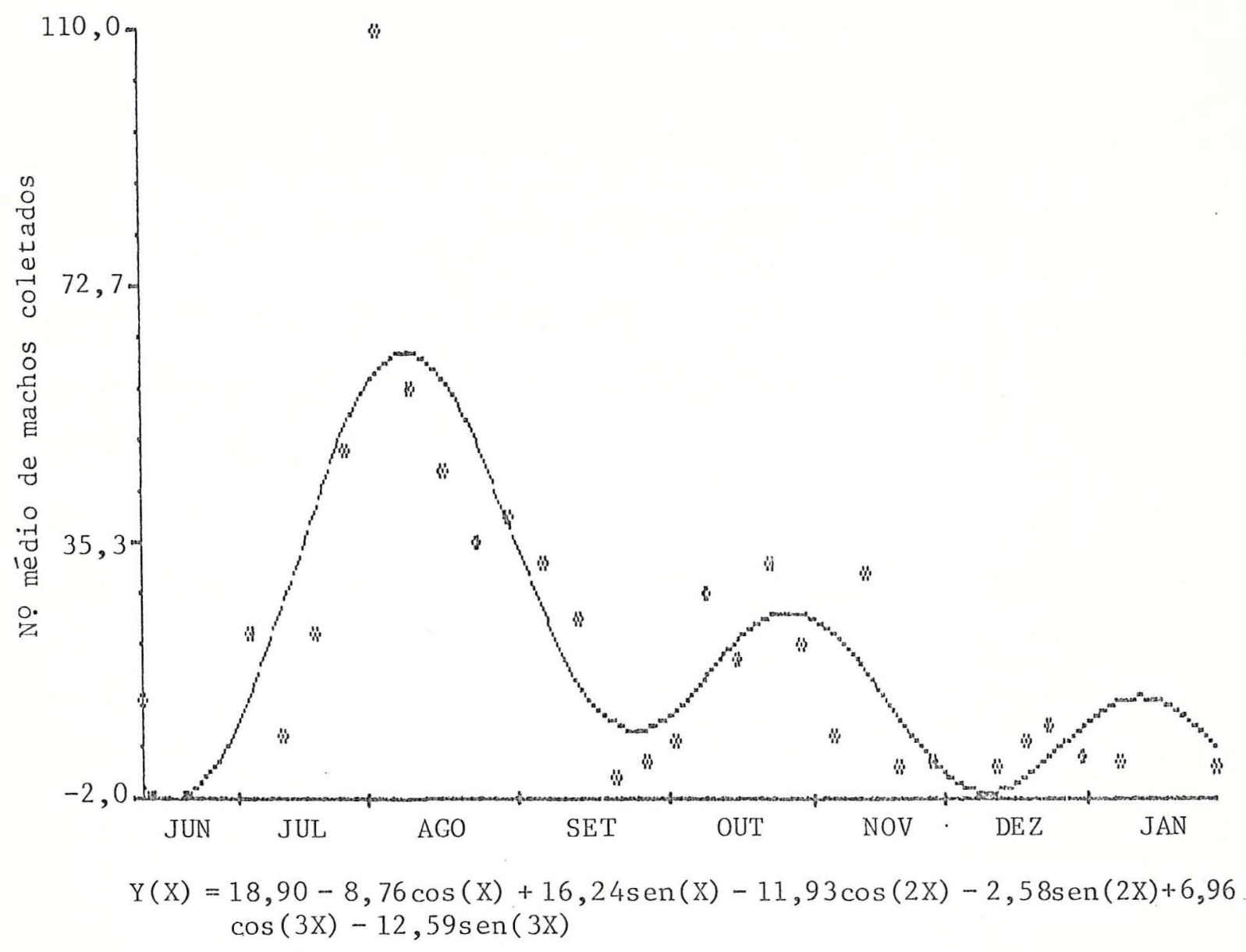

FIGURA 1 - Pomar A - 'Ponkan' - 19 Ano.

TABELA 10 - Anālise de variância para variedade 'Ponkan' - 10 Ano-Pomar A.

\begin{tabular}{lcccc}
\hline Fontes de Variação & G.L. & S.Q. & Q.M. & F' \\
\hline Regr. H. 19 Grau & 2 & 5616,81 & 2808,41 & $12,48 * *$ \\
Desvio Regr. H. 19 Grau & 26 & 9831,95 & 378,15 & - \\
\hline Ad. Regr. H. 29 Grau & 2 & 2433,68 & 1216,84 & $5,41 *$ \\
Desvio Regr. H. 20 Grau & 24 & 7398,27 & 308,26 & - \\
\hline Ad. Regr. H. 39 Grau & 2 & 2445,59 & 1222,80 & $5,43 *$ \\
Desvio Regr. H. 39 Grau & 22 & 4952,68 & 225,12 & - \\
\hline
\end{tabular}




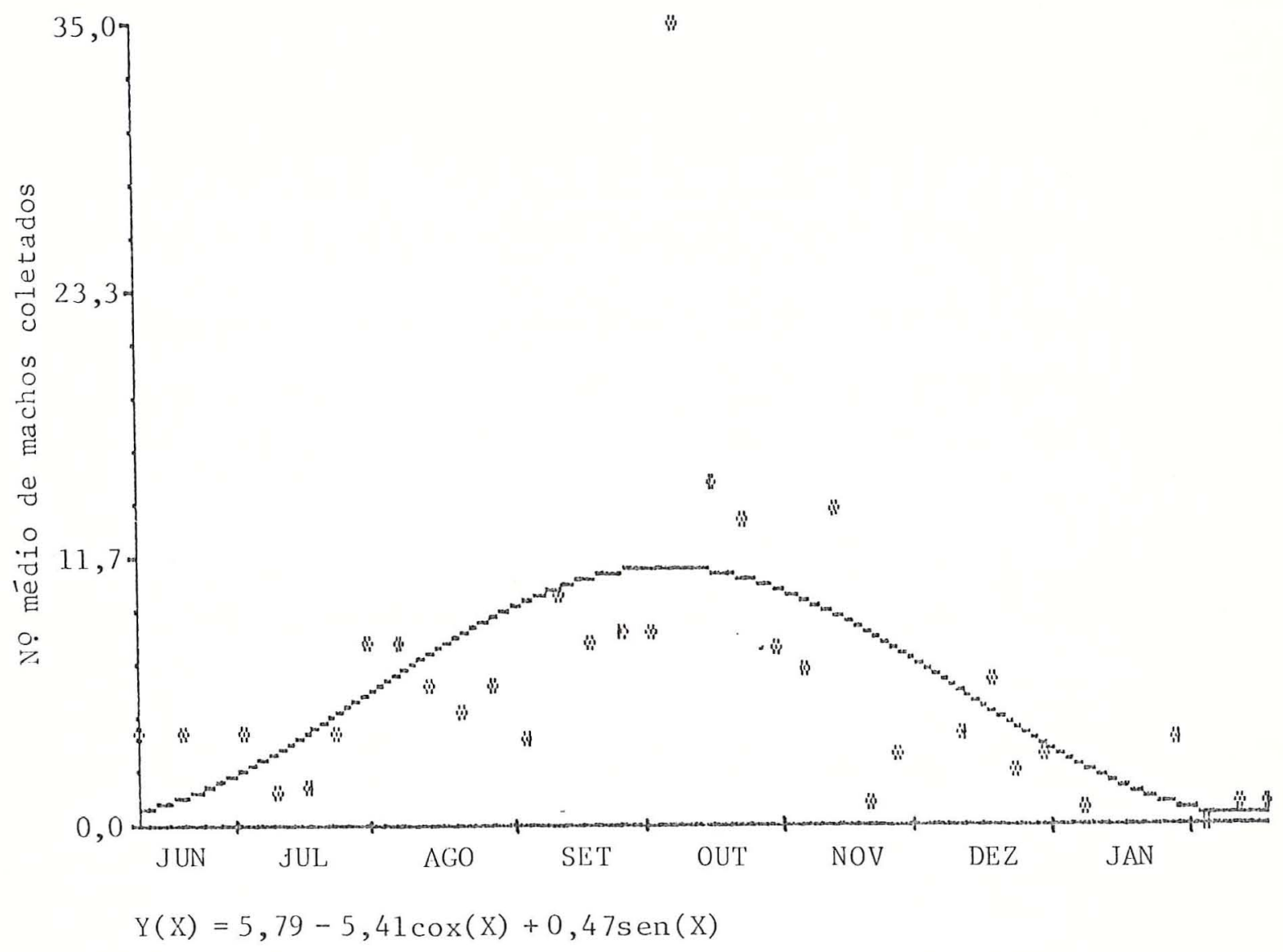

FIgURA 2 - P'omar A - 'Natal' - 19. Ano.

TABELA 11 - Análise de variância para variedade 'Natal' - 19 Ano - Pomar A.

\begin{tabular}{lcccc}
\hline Fontes de Variação & G.L. & S.Q. & Q.M. & F \\
\hline Regr. H. 19. Grau & 2 & 472,67 & 236,34 & $8,40 * *$ \\
Desvio Regr. H. 19 Grau & 30 & 844,05 & 28,14 & - \\
\hline
\end{tabular}




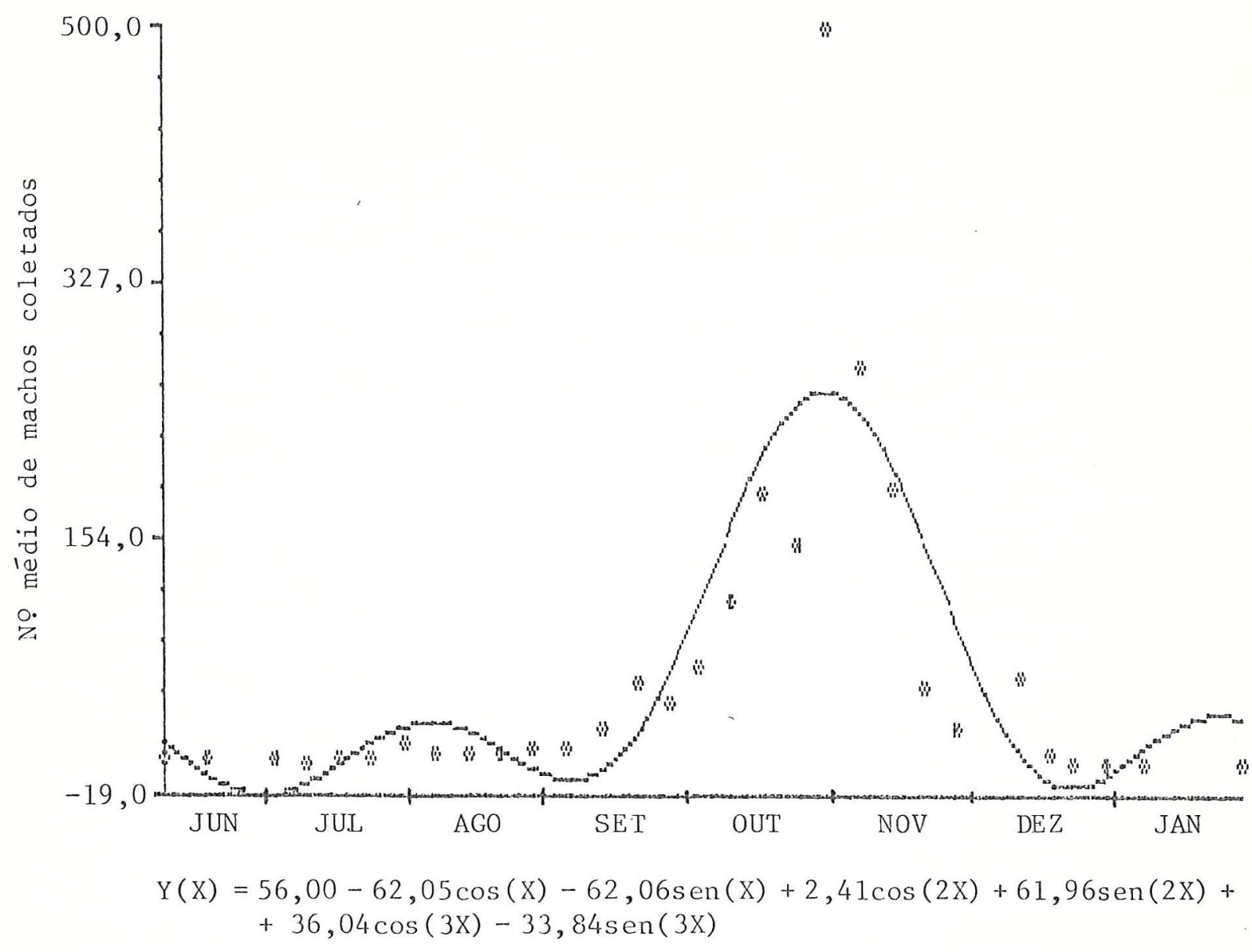

FIgURA 3 - Pomar A - 'Murcote' - 19 Ano.

TABELA 12 - Anālise de variância para variedade 'Murcote' - 19 Ano-Pomar A.

\begin{tabular}{lcccc}
\hline Fontes de Variação & G.L. & S.Q. & Q.M. & F \\
\hline Regr. H. 19 Grau & 2 & 130730,72 & 65365,36 & $15,15 * *$ \\
Desvio Regr. H. 19 Grau & 27 & 203101,13 & 7522,26 & - \\
\hline Ad. Regr. H. 29 Grau & 2 & 72219,63 & 36109,82 & $8,37 * *$ \\
Desvio Regr. H. 29 Grau & 25 & 130881,49 & 5235,26 & - \\
\hline Ad. Regr. H. 39 Grau & 2 & 31620,49 & 15810,25 & $3,66 *$ \\
Desvio Regr. H. 39 Grau & 23 & 99261,00 & 4315,70 & - \\
\hline
\end{tabular}




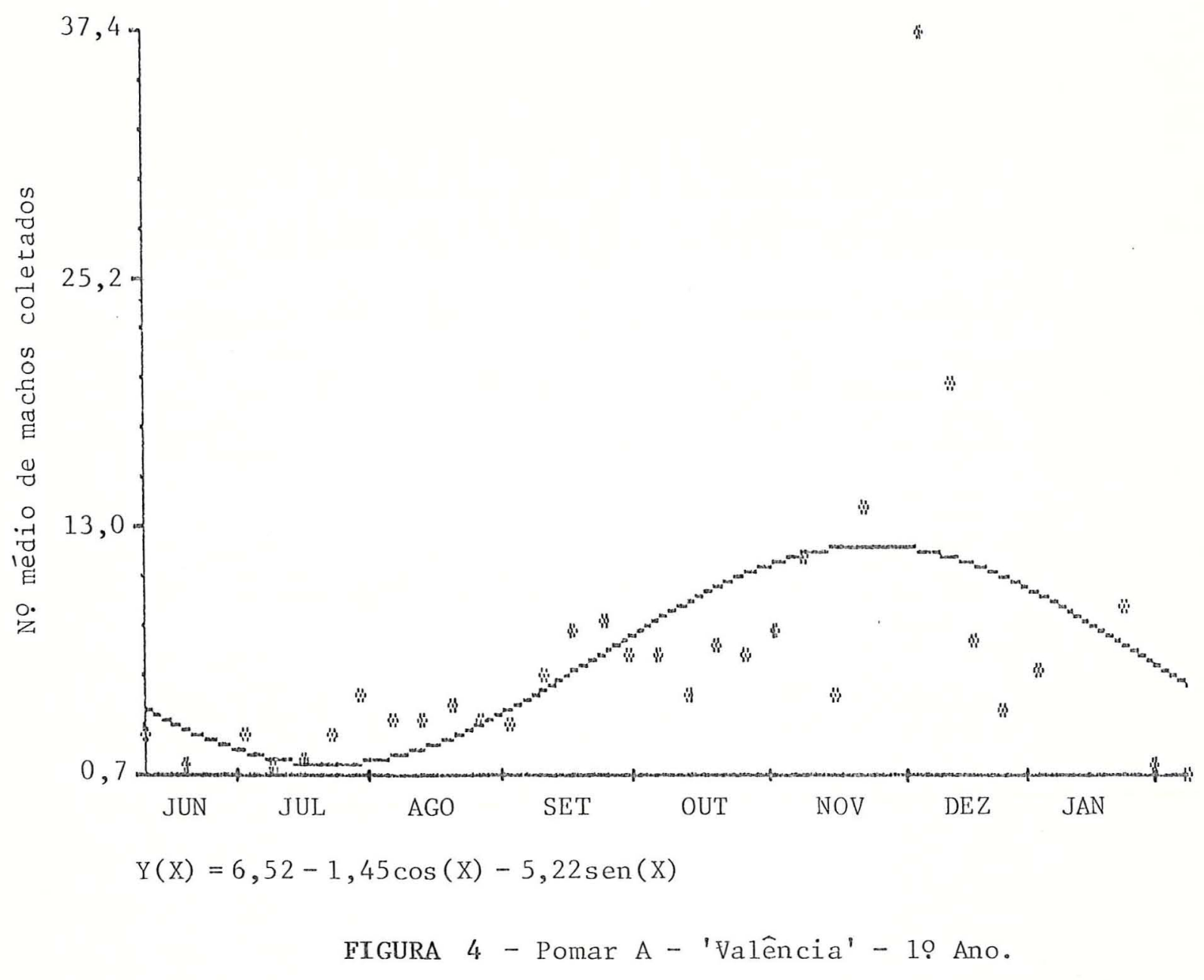

TABELA 13 - Anālise de variância para variedade 'Valência'-10 Ano - Pomar A.

\begin{tabular}{lcrrr}
\hline Fontes de Variação & G.L. & S.Q. & Q.M. & F \\
\hline Regr. H. 19 Grau & 2 & 483,69 & 241,85 & $6,94 * *$ \\
Desvio Regr. H. 19 Grau & 29 & 1010,84 & 34,86 & - \\
\hline
\end{tabular}




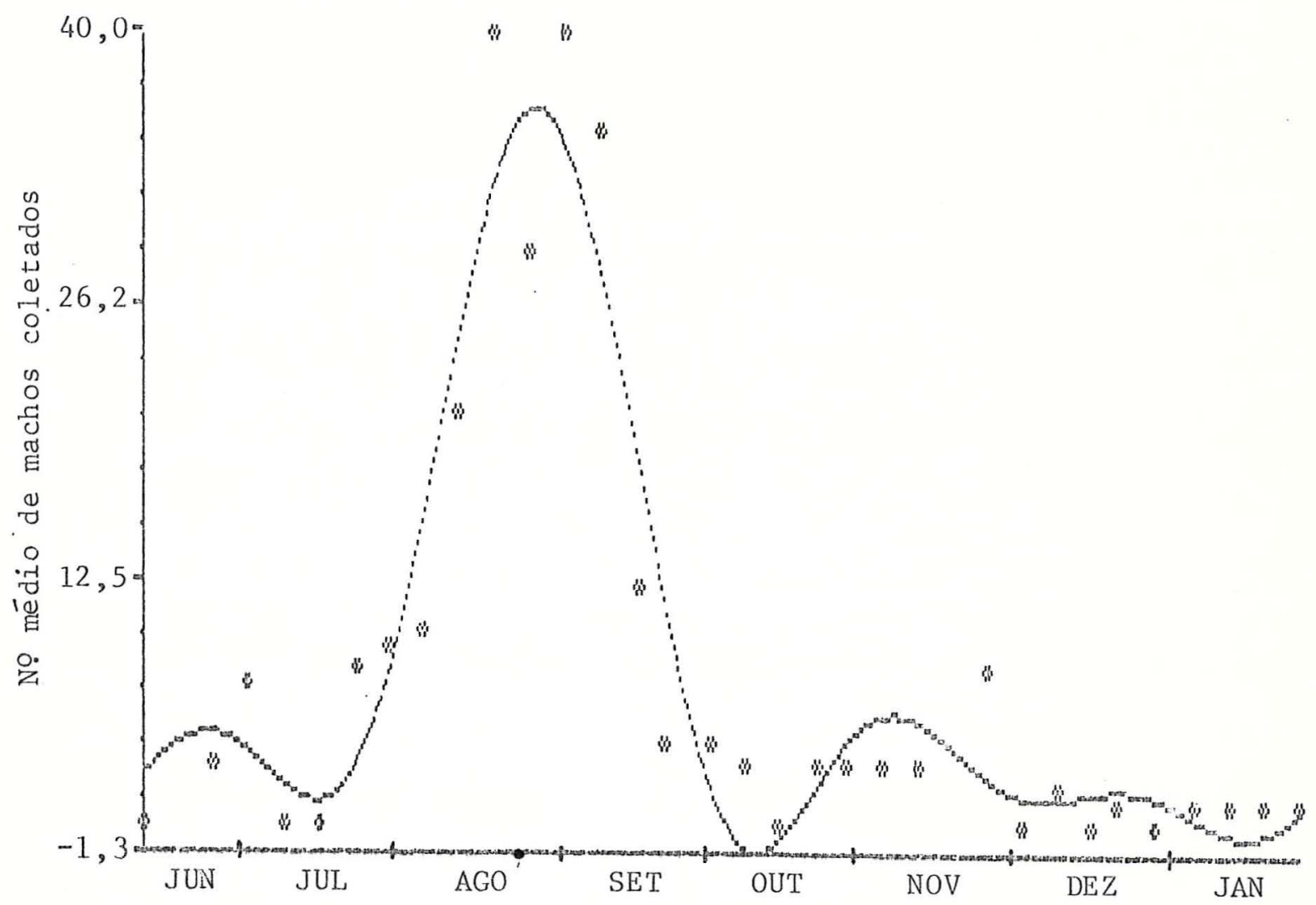

$$
\begin{aligned}
Y(X)= & 7,54-6,54 \cos (X)+8,13 \operatorname{sen}(X)-2,62 \cos (2 X)-7,21 \operatorname{sen}(2 X)+5,92 \\
& \cos (3 X)+3,33 \operatorname{sen}(3 X)-3,61 \cos (4 X)+1,20 \operatorname{sen}(4 X)
\end{aligned}
$$

FIGURA 5 - Pomar A - 'Ponkan' - 20. Ano.

TABELLA 14 - Anālise de variância para variedade 'Ponkan' - 20 Ano - Pomar A.

\begin{tabular}{lcccc}
\hline Fontes de Variação & G.L. & S.Q. & Q.M. & F \\
\hline Regr. H. 19 Grau & 2 & 1869,32 & 934,66 & $46,39 * *$ \\
Desvio Regr. H. 19 Grau & 29 & 2450,17 & 84,49 & - \\
\hline Ad. Regr. H. 20 Grau & 2 & 1034,86 & 517,43 & $25,68 * *$ \\
Desvio Regr. H. 29 Grau & 27 & 1415,32 & 52,42 & - \\
\hline Ad. Regr. H. 39 Grau & 2 & 723,07 & 361,54 & $17,94 * *$ \\
Desvio Regr. H. 30 Grau & 25 & 692,25 & 27,69 & - \\
\hline Ad. Regr. H. 49 Grau & 2 & 228,77 & 114,39 & $5,68 * *$ \\
Desvio Regr. H. 49 Grau & 23 & 463,48 & 20,15 & -
\end{tabular}




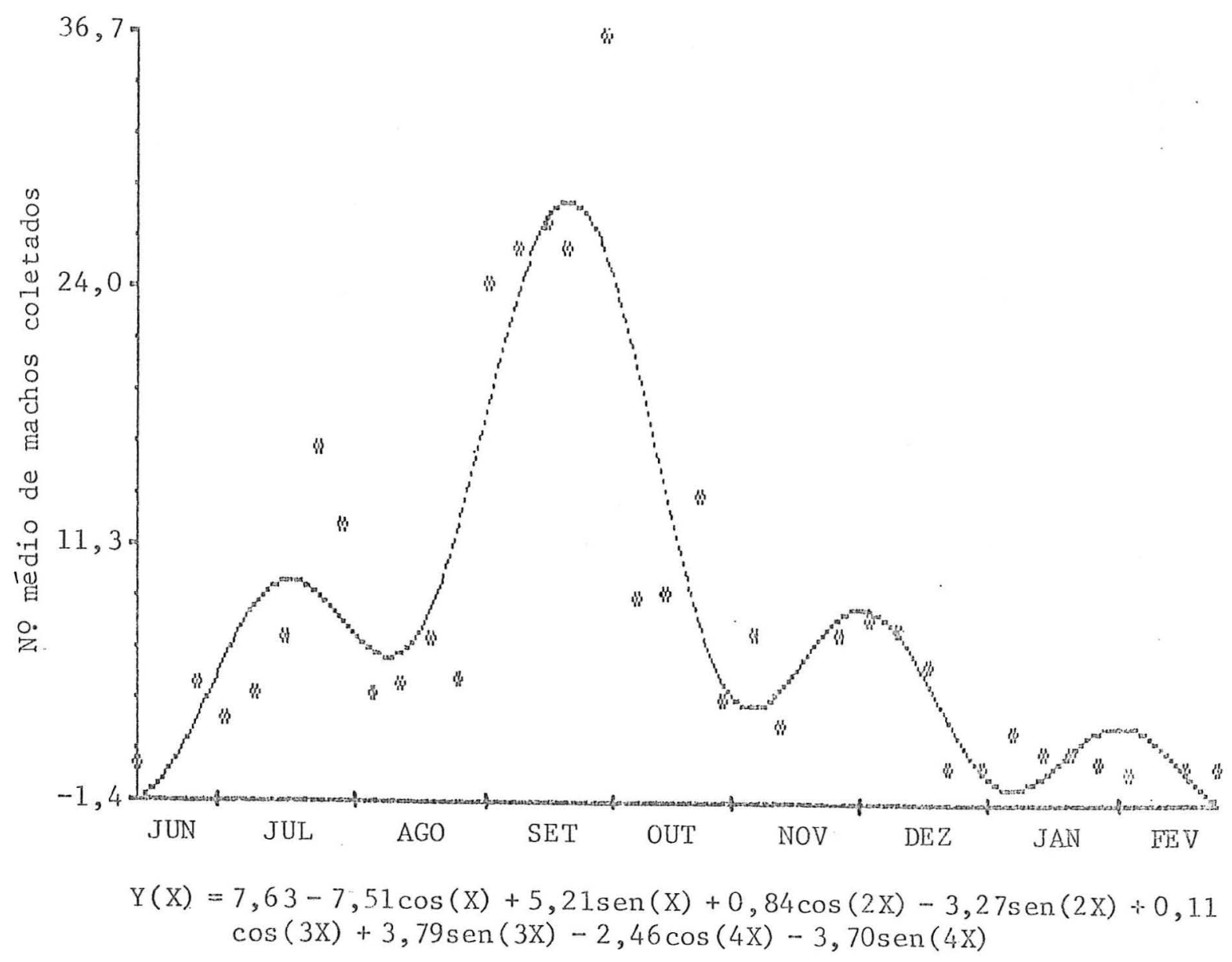

$$
\text { FIGURA } 6 \text { - Pomar A - 'Nata1' - 29 Ano. }
$$

TABELA 15 - Anảilise de variância para variedade 'Natal' - 20 Ano - Pomar A.

\begin{tabular}{lcccc}
\hline Fontes de Variação & G.L. & S.Q. & Q.M. & F \\
\hline Regr. H. 1.9 Grau & 2 & 1481,25 & 740,63 & $32,22 * *$ \\
Desvio Regr. H. 19 Grau & 32 & 1454,99 & 45,47 & - \\
\hline Ad. Regr. H. 20 Grau & 2 & 204,72 & 102,36 & $4,45 *$ \\
Desvio Regr. H. 29 Grau & 30 & 1250,27 & 41,68 & - \\
\hline Ad. Regr. H. 39 Grau & 2 & 323,15 & 161,58 & $7,03 * *$ \\
Desvio Regr. H. 39 Grau & 28 & 927,12 & 33,11 & - \\
\hline Ad. Regr. H. 49 Grau & 2 & 329,30 & 164,65 & $7,16 * *$ \\
Desvio Regr. H. 49 Grau & 26 & 597,82 & 22,99 & - \\
\hline
\end{tabular}




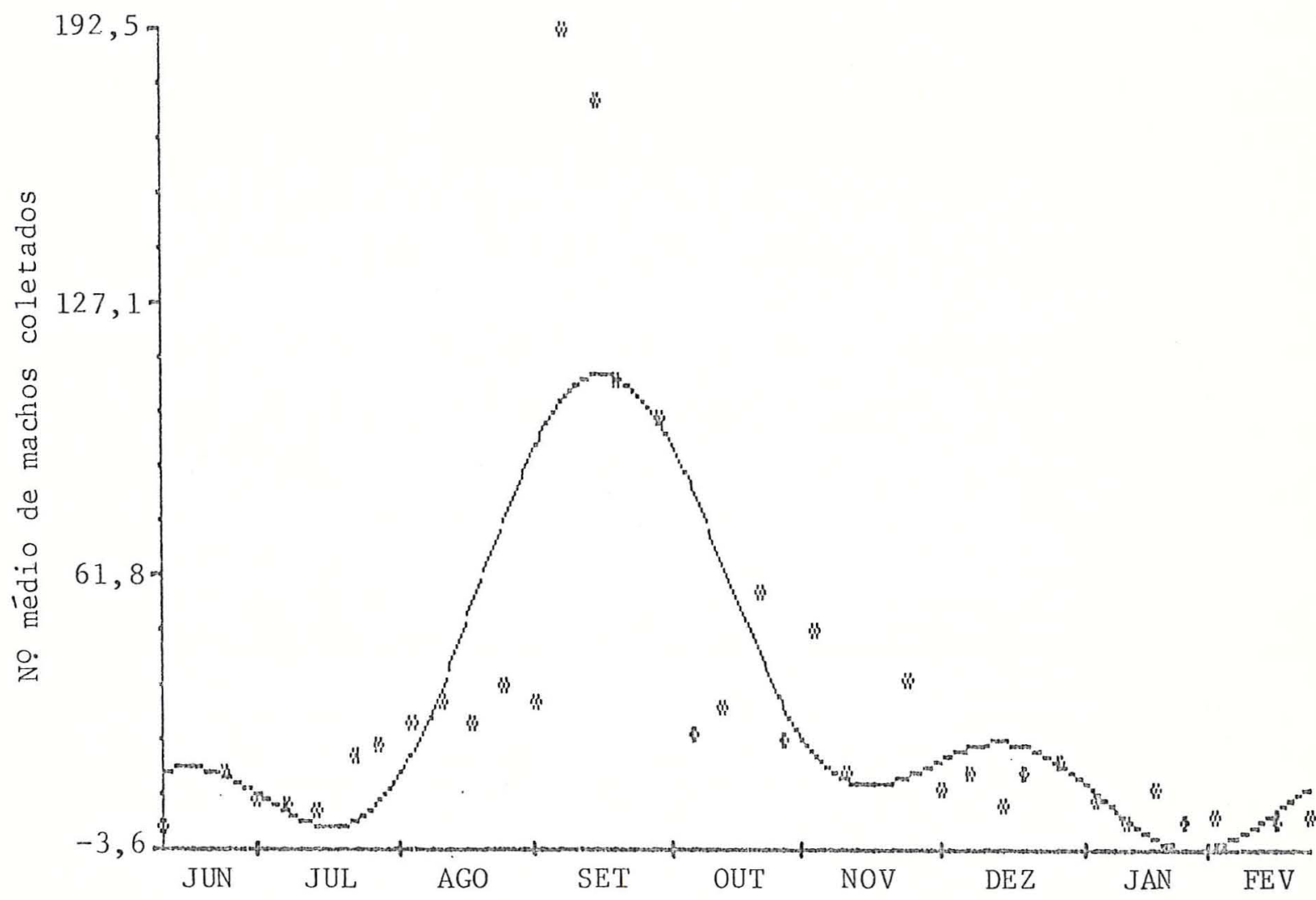

$$
\begin{aligned}
Y(X)= & 29,53-33,35 \cos (X)+19,93 \operatorname{sen}(X)+6,41 \cos (2 X)-21,92 \operatorname{sen}(2 X)+ \\
& +7,57 \cos (3 X)+17,05 \operatorname{sen}(3 X) .
\end{aligned}
$$

FIgURA 7 - Pomar A - 'Murcote' - 20. Ano.

TABELA 16 - Anālise de variância para variedade 'Murcote' - 20 Ano-Pomar A.

\begin{tabular}{lcccc}
\hline Fontes de Variação & G.L. & S.Q. & Q.M. & F \\
\hline Regr. H. 19 Grau & 2 & 28036,86 & 14018,43 & $15,04 * *$ \\
Desvio Regr. H. 19 Grau & 32 & 41823,38 & 1306,98 & - \\
\hline Ad. Regr. H. 29 Grau & 2 & 9480,00 & 4740,00 & $5,09 *$ \\
Desvio Regr. H. 29 Grau & 30 & 32343,38 & 1078,11 & - \\
\hline Ad. Regr. H. 39 Grau & 2 & 6253,36 & 3126,68 & $3,36 *$ \\
Desvio Regr. H. 39 Grau & 28 & 26090,02 & 931,79 & - \\
\hline
\end{tabular}




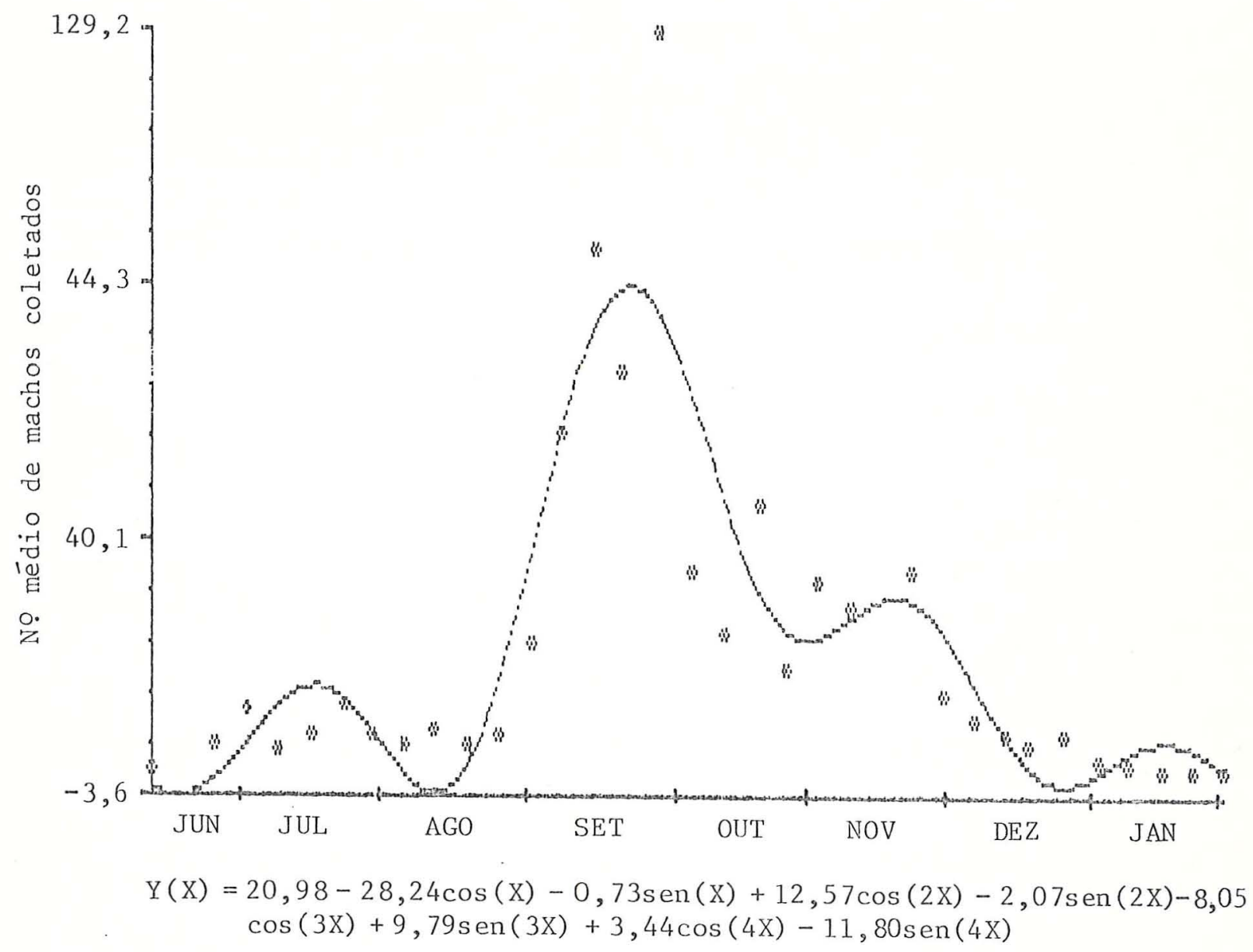

FIgurA 8 - Pomar A - 'Valência' - 29 Ano.

TABELA 17 - Anālise de variância para variedade 'Valência' - 20 Ano-Pomar A.

\begin{tabular}{lcccc}
\hline Tontes de Variação & G.L. & S.Q. & Q.M. & F \\
\hline Regr. H. 19 Grau & 2 & 13062,69 & 6531,35 & $27,40 * *$ \\
Desvio Regr. H. 19 Grau & 30 & 14031,78 & 467,73 & - \\
\hline Ad. Regr. H. 29 Grau & 2 & 2963,58 & 1481,79 & $6,22 *$ \\
Desvio Regr. H. 29 Grau & 28 & 11068,20 & 395,29 & - \\
\hline Ad. Regr. H. 39 Grau & 2 & 3000,65 & 1500,33 & $6,29 * *$ \\
Desvio Regr. H. 39 Grau & 26 & 8067,55 & 310,29 & - \\
\hline Ad. Regr. H. 49 Grau & 2 & 2345,72 & 1172,86 & $4,92 *$ \\
Desvio Regr. H. 40 Grau & 24 & 5721,84 & 238,41 & -
\end{tabular}




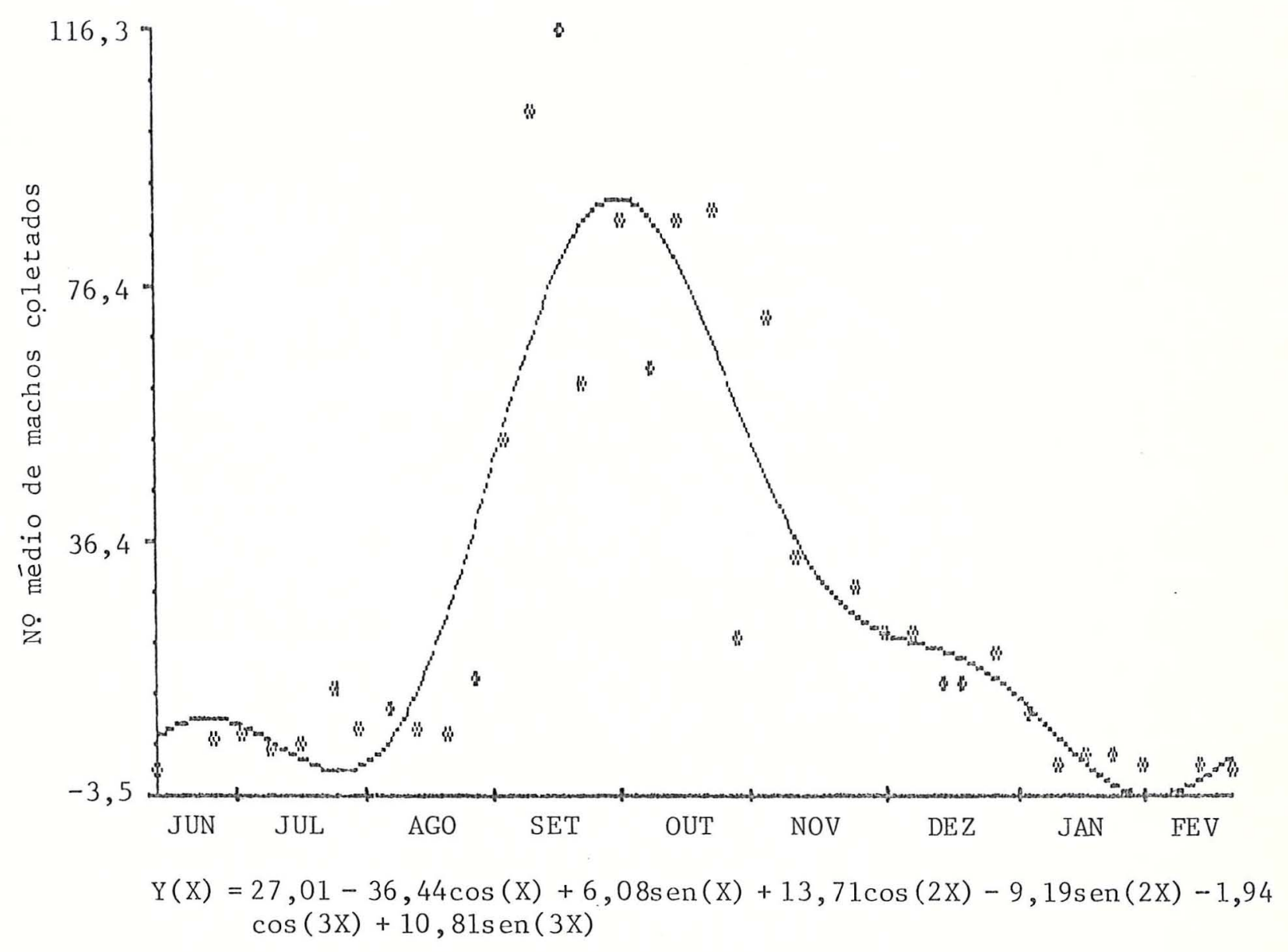

FIGURA 9 - Pomar A - 'Pera' - 2O Ano.

TABELA 18 - Análise de variância para variedade 'Pera' - 2ọ Ano-Pomar A.

\begin{tabular}{lcccc}
\hline Fontes de Variação & G.L. & S.Q. & Q.M. & F \\
\hline Regr. H. 19 Grau & 2 & 24873,24 & 12436,62 & $46,07 * *$ \\
Desvio Regr. H. 19 Grau & 32 & 14392,34 & 449,76 & - \\
\hline Ad. Regr. H. 29 Grau & 2 & 4786,53 & 2393,27 & $8,87 * *$ \\
Desvio Regr. H. 29 Grau & 30 & 9605,81 & 320,19 & - \\
\hline Ad. Regr. H. 39 Grau & 2 & 2047,64 & 1023,82 & $3,79 *$ \\
Desvio Regr. H. 39 Grau & 28 & 7558,17 & 269,93 & - \\
\hline
\end{tabular}




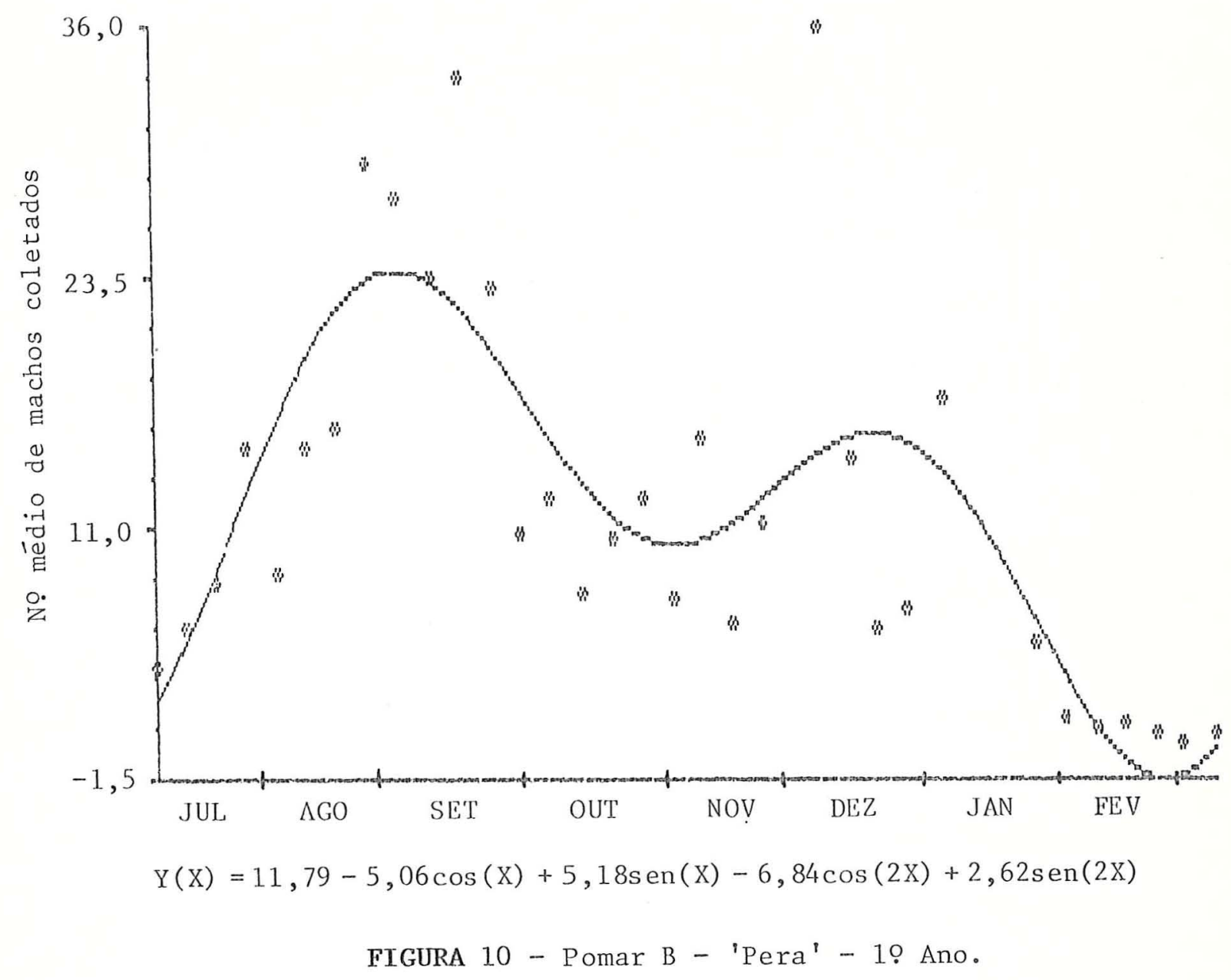

TABELA 19 - Anālise de variância para variedade 'Pera' - 10 Ano - Pomar B.

\begin{tabular}{lcccc}
\hline Fontes de Variação & G.L. & S.Q. & Q.M. & F \\
\hline Regr. H. 19 Grau & 2 & 982,71 & 491,36 & $12,12 * *$ \\
Desvio Regr. H. 19 Grau & 30 & 2031,68 & 67,72 & - \\
\hline Ad. Regr. H. 29 Grau & 2 & 896,78 & 448,39 & $11,06 * *$ \\
Desvio Regr. H. 29 Grau & 28 & 1134,89 & 40,53 & - \\
\hline
\end{tabular}




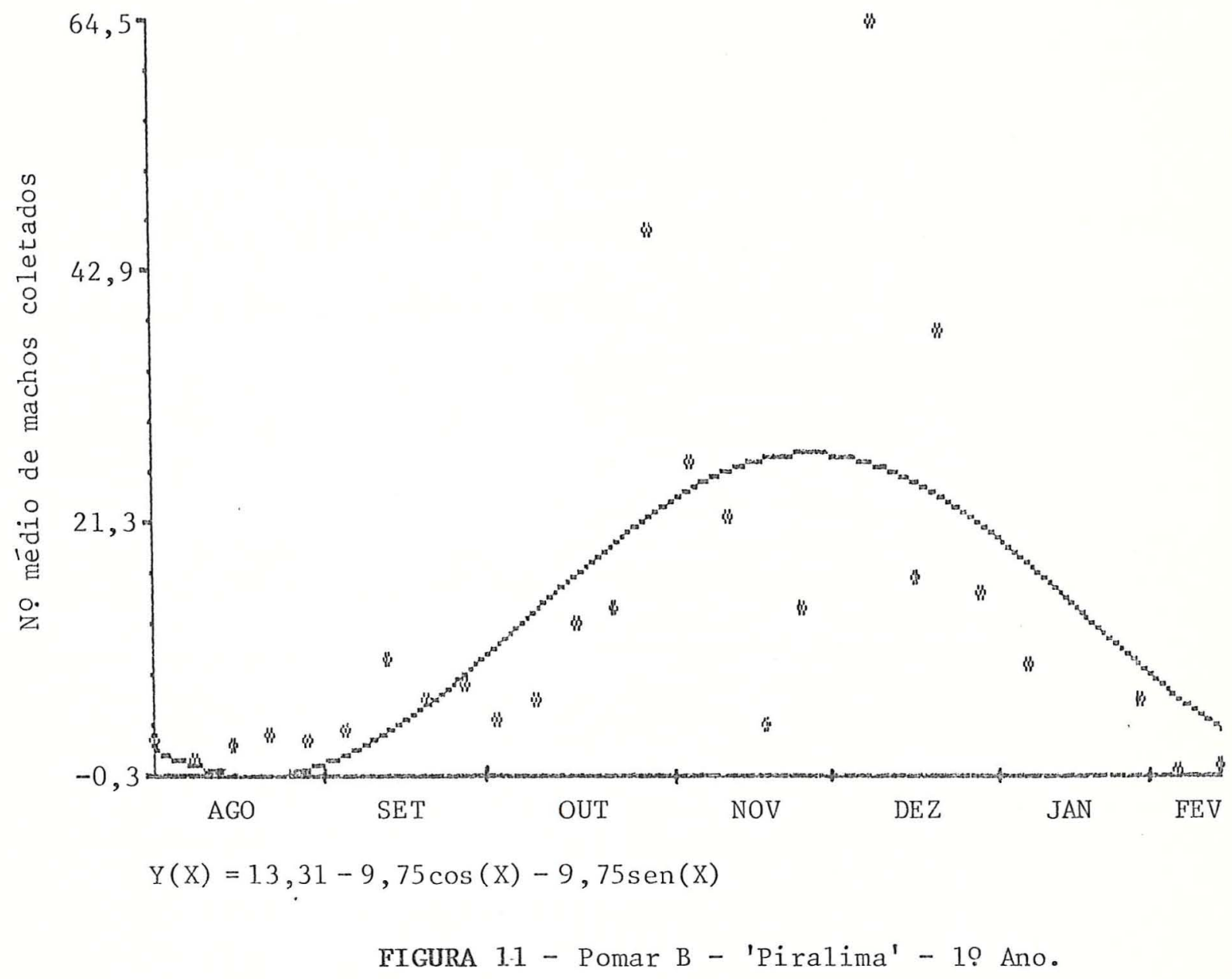

TABElA 20 - Anālise de variância para variedade 'Piralima'-10 Ano-Pomar B.

\begin{tabular}{lrrrc}
\hline Fontes de Variação & G.L. & S.Q. & Q.M. & F \\
\hline Regr. H. 19. Grau & 2 & 2572,81 & 1286,41 & 8,61 *** \\
Desvio Regr. H. 19 Grau & 23 & 3434,54 & 149,33 & - \\
\hline
\end{tabular}




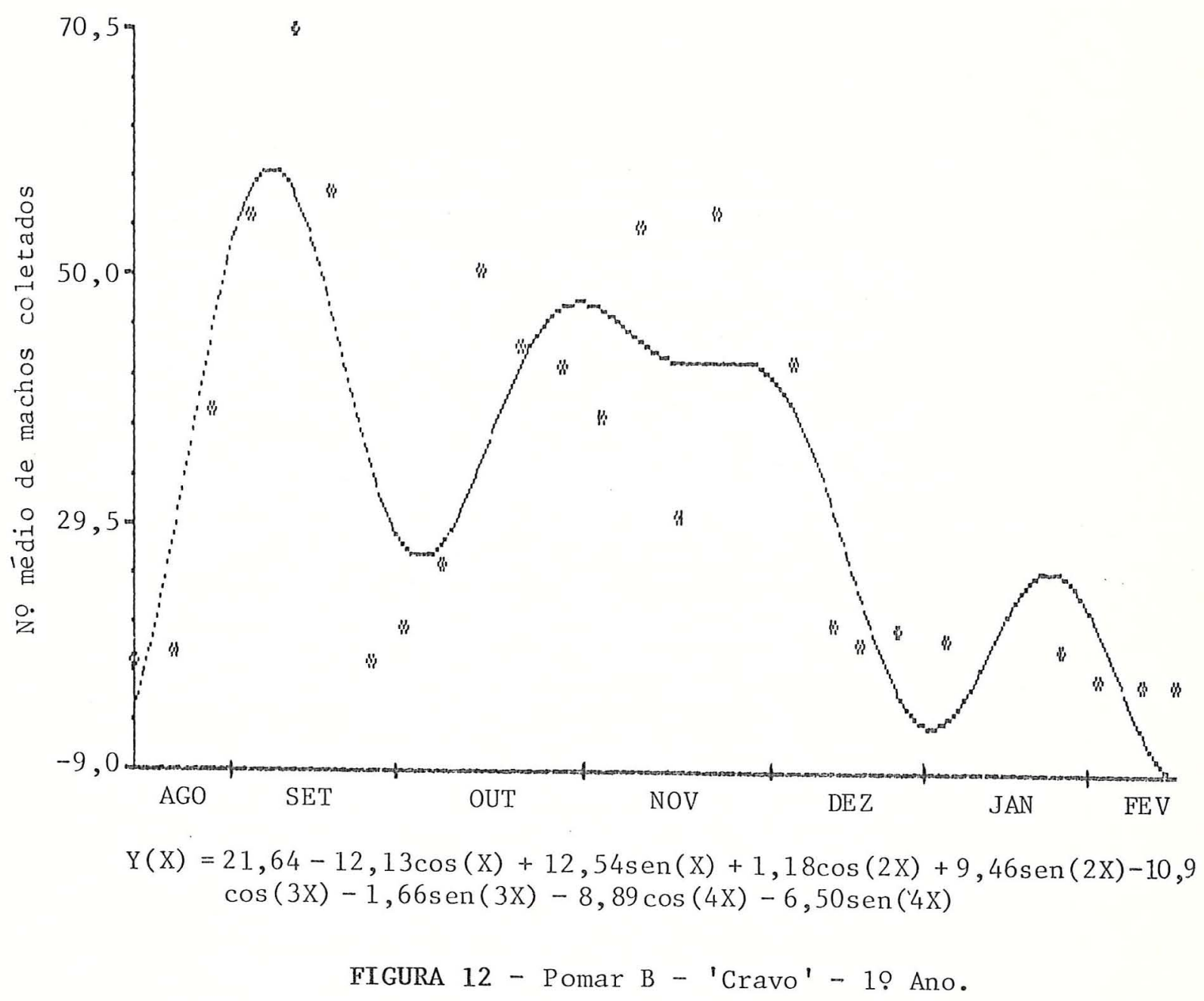

TABEla 21 - Análise de variância para variedade 'Cravo' - 19 ? Ano - Pomar B.

\begin{tabular}{lcccc}
\hline Fontes de Variação & G.L. & S.Q. & Q.M. & F \\
\hline Regr. H. 19 Grau & 2 & 3579,95 & 1789,98 & $9,21 * *$ \\
Desvio Regr. H. 19 Grau & 22 & 7520,55 & 341,84 & - \\
\hline Ad. Regr. H. 29 Grau & 2 & 1397,57 & 698,79 & $3,60 *$ \\
Desvio Regr. H. 29 Grau & 20 & 6122,98 & 306,15 & - \\
\hline Ad. Regr. H. 39 Grau & 2 & 1442,68 & 721,34 & $3,71 *$ \\
Desvio Regr. H. 39 Grau & 18 & 4680,30 & 260,02 & - \\
\hline Ad. Regr. H. 49 Grau & 2 & 1571,88 & 785,94 & $4,05 *$ \\
Desvio Regr. H. 49 Grau & 16 & 3108,43 & 194,28 & - \\
\hline
\end{tabular}




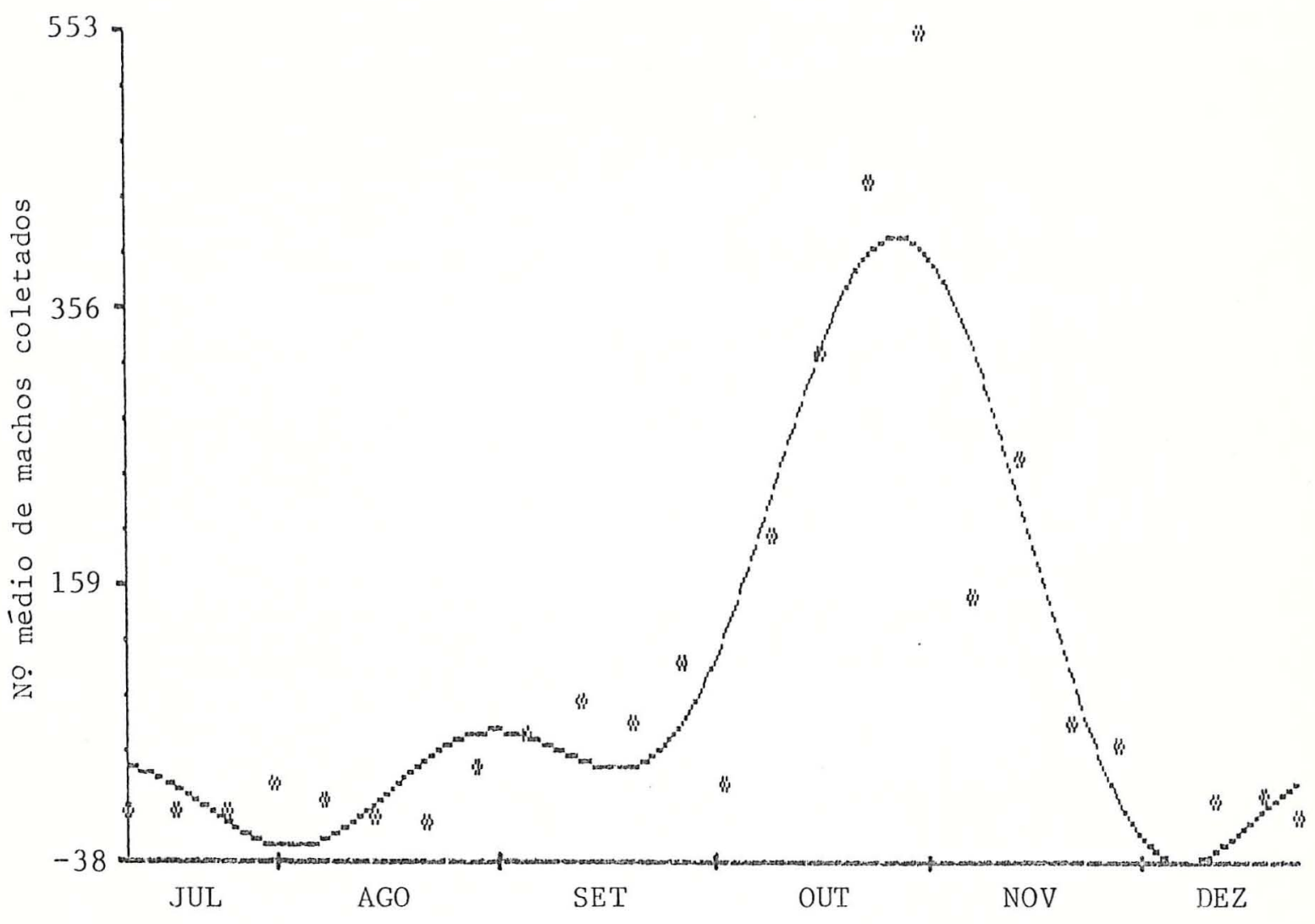

$$
\begin{aligned}
Y(X)= & 103,75-91,67 \cos (X)-117,90 \operatorname{sen}(X)-47,10 \cos (2 X)+81,32 \operatorname{sen}(2 X)+ \\
& +64,86 \cos (3 X)+12,61 \operatorname{sen}(3 X)
\end{aligned}
$$

$$
\text { FIGURA } 13 \text { - Pomar B - 'Murcote' - 19 Ano. }
$$

TABELA 22 - Análise de variância para variedade 'Murcote' - 19 Ano-Pomar B.

\begin{tabular}{lcccc}
\hline Fontes de Variação & G.L. & S.Q. & Q.M. & F \\
\hline Regr. H. 19 Grau & 2 & 278792,12 & 139396,06 & $27,74 * *$ \\
Desvio Regr. H. 19 Grau & 21 & 230334,85 & 10968,33 & - \\
\hline Ad. Regr. H. 29 Grau & 2 & 92078,10 & 46039,05 & $9,16 * *$ \\
Desvio Regr. H. 29 Grau & 19 & 138256,75 & 7276,67 & - \\
\hline Ad. Regr. H. 39 Grau & 2 & 52819,08 & 26409,54 & $5,25 *$ \\
Desvio Regr. H. 39 Grau & 17 & 85437,68 & 5025,75 & - \\
\hline
\end{tabular}




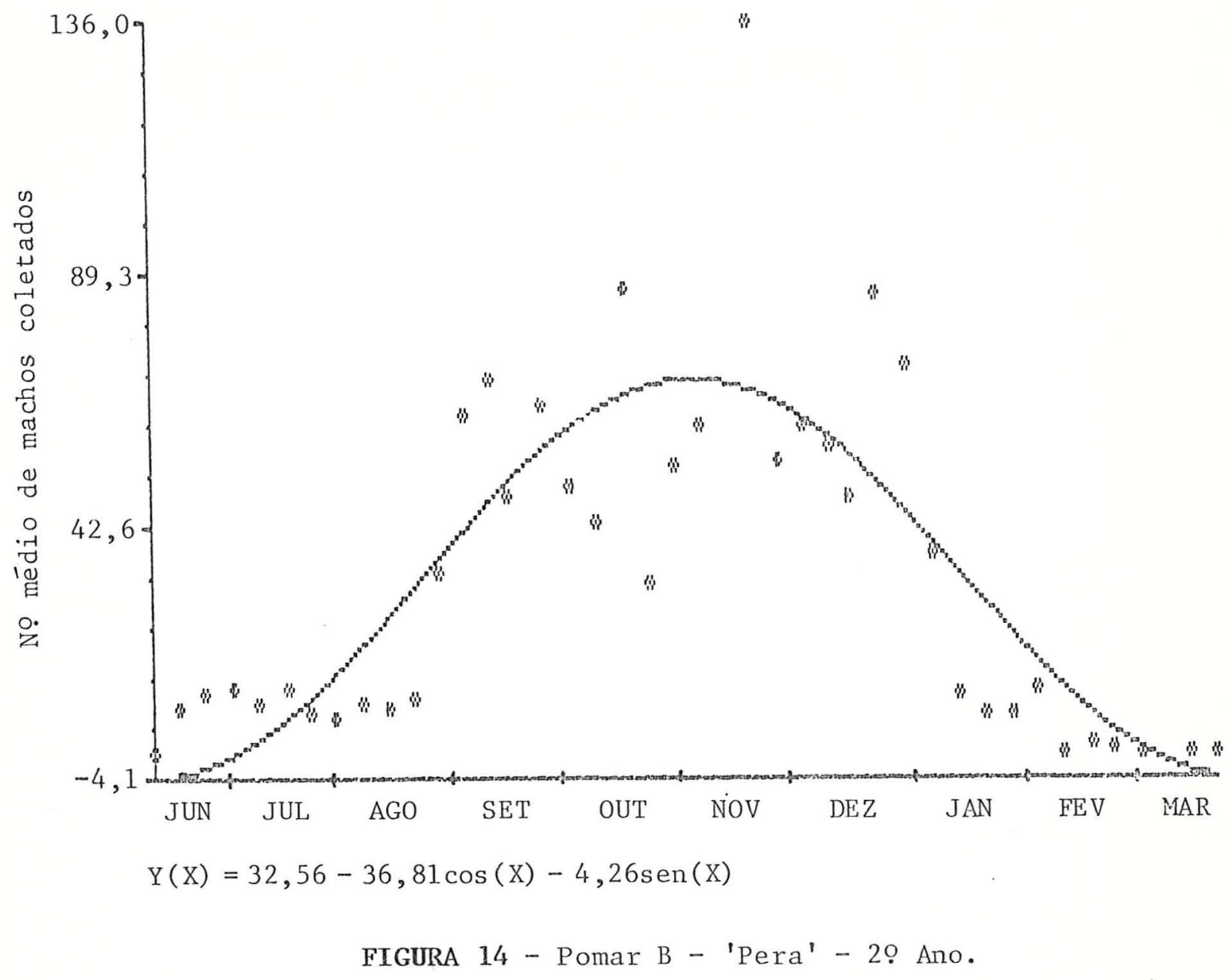

TABELA 23 - Análise de variância para variedade 'Pera' - 20 Ano-Pomar B.

\begin{tabular}{lcrrr}
\hline Fontes de Variação & G.L. & S.Q. & Q.M. & F \\
\hline Regr. H. 10 Grau & 2 & 26405,29 & 13202,65 & $36,44 * *$ \\
Desvio Regr. H. 10 Grau & 37 & 13404,67 & 362,29 & \\
\hline
\end{tabular}




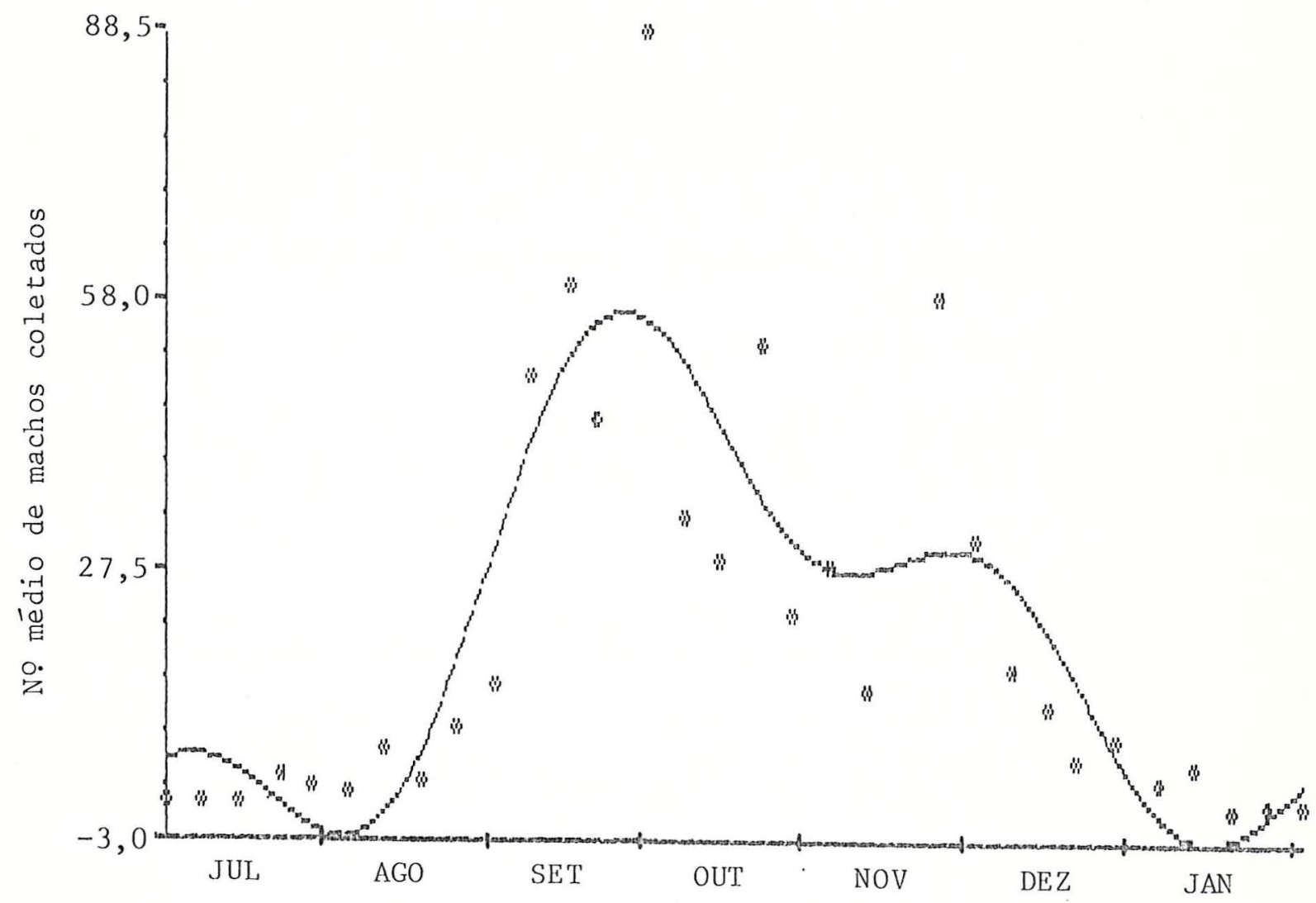
$\begin{aligned} Y(X)= & 19,83-23,98 \cos (X)-0,34 \operatorname{sen}(X)+3,59 \cos (2 X)-5,63 \operatorname{sen}(2 X)+3,56 \\ & \cos (3 X)+9,39 \operatorname{sen}(3 X)\end{aligned}$ FIGURA 15 - Pomar B - 'Piralima' - 2ọ Ano.

TABELA 24-Anälise de variância para variedade 'Piralima' - 20 Ano-Pomar B.

\begin{tabular}{lcccc}
\hline Fontes de Variação & G.L. & S.Q. & Q.M. & F \\
\hline Regr. H. 19 Grau & 2 & 9010,90 & 4505,45 & $26,43 * *$ \\
Desvio Regr. H. 19 Grau & 28 & 6411,65 & 228,99 & - \\
\hline Ad. Regr. H. 29 Grau & 2 & 709,94 & 354,97 & 2,08 \\
Desvio Regr. H. 29 Grau & 26 & 5701,70 & 219,30 & - \\
\hline Ad. Regr. H. 39 Grau & 2 & 1610,84 & 805,42 & $4,73 *$ \\
Desvio Regr. H. 39 Grau & 24 & 4090,87 & 170,45 & - \\
\hline
\end{tabular}




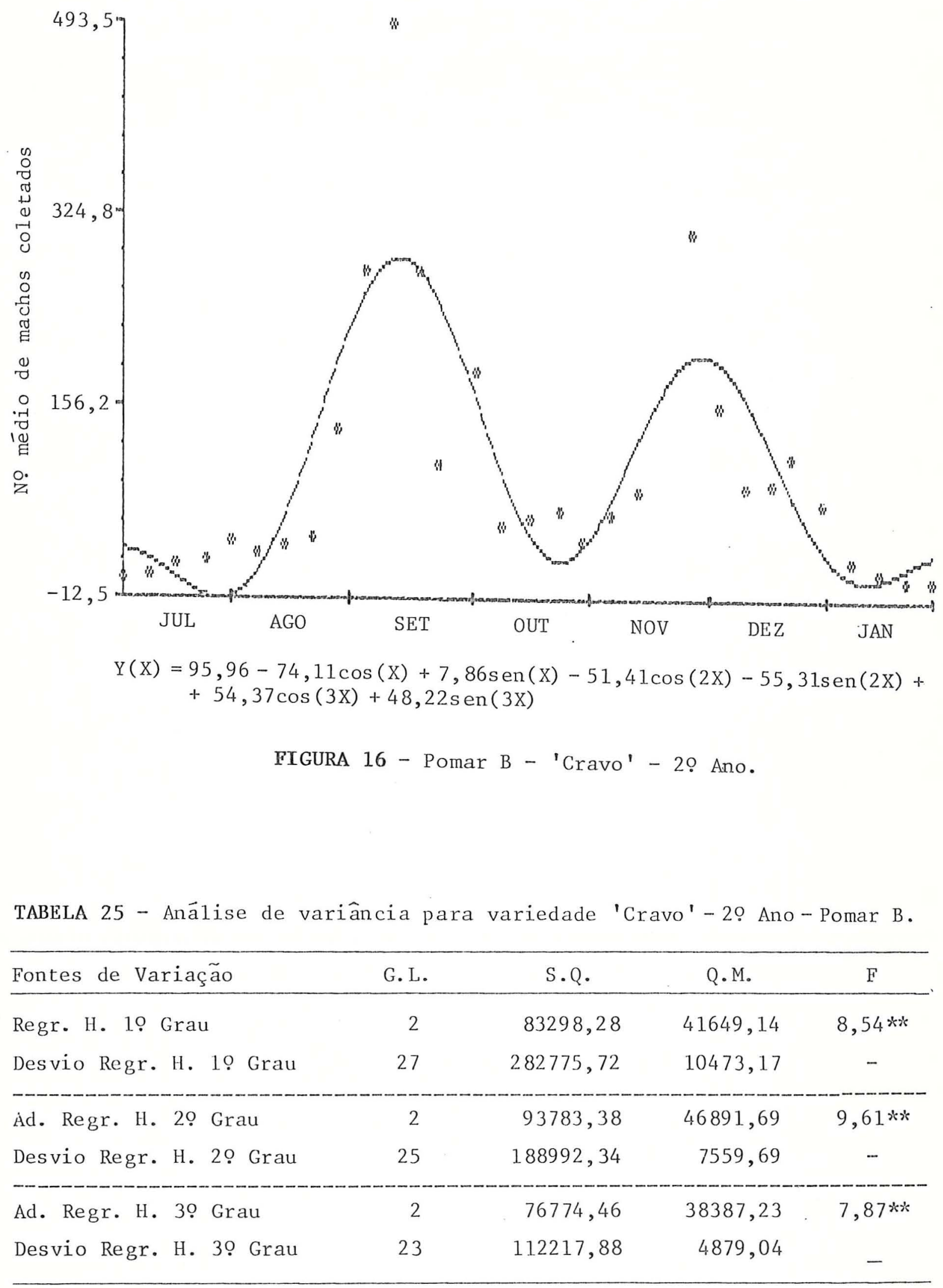




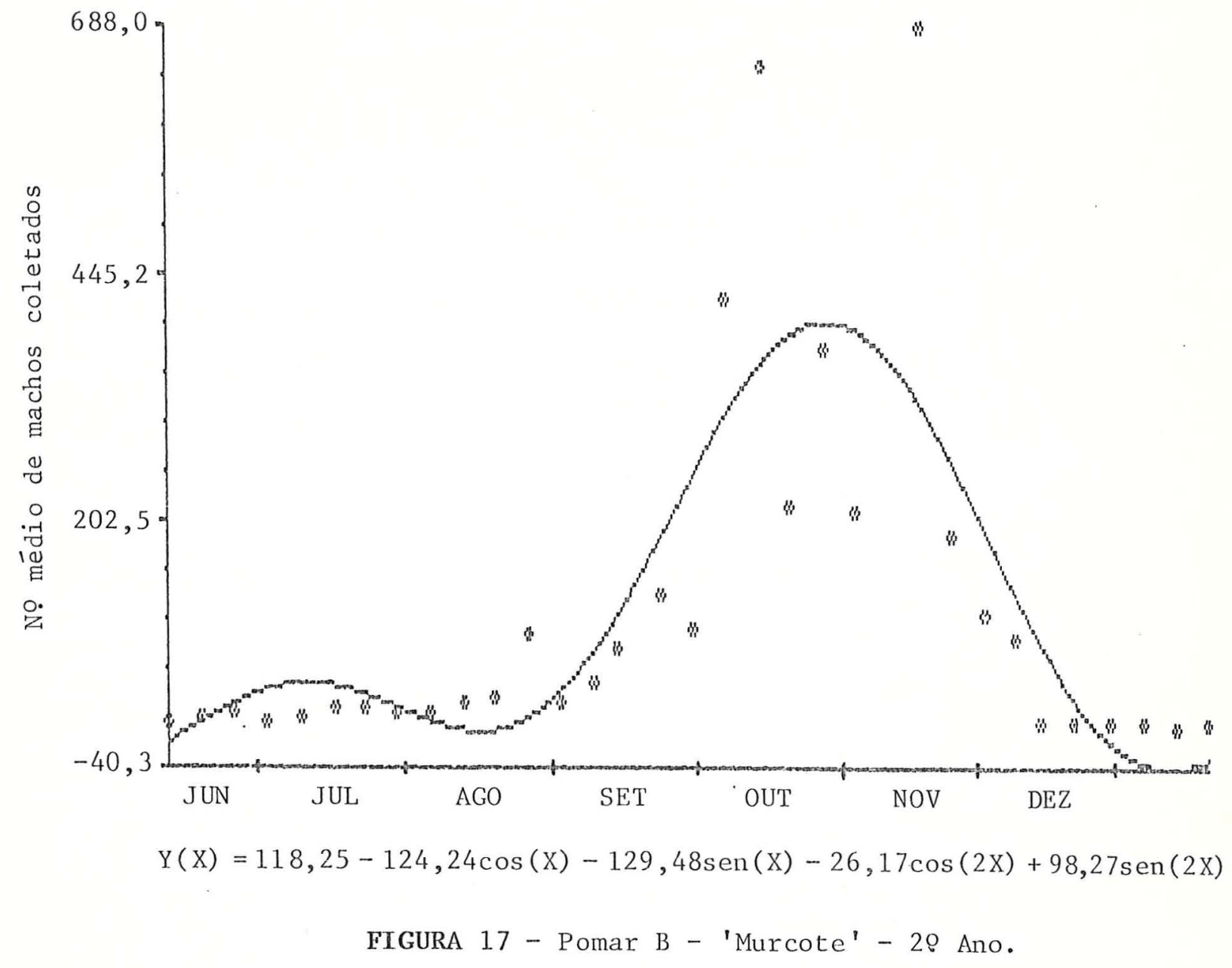

TABEla 26 - Anälise de variância para variedade 'Murcote' - 20. Ano-Pomar B.

\begin{tabular}{lcccc}
\hline Fontes de Variação & G.L. & S.Q. & Q.M. & F \\
\hline Regr. H. 19 Grau & 2 & 477480,50 & 238740,25 & $17,80 * *$ \\
Desvio Regr. H. 19 Grau & 29 & 525536,50 & 18121,95 & - \\
\hline Ad. Regr. H. 29 Grau & 2 & 163315,81 & 81657,91 & $6,09 * *$ \\
Desvio Regr. H. 29 Grau & 27 & 362220,69 & 13415,58 & - \\
\hline
\end{tabular}




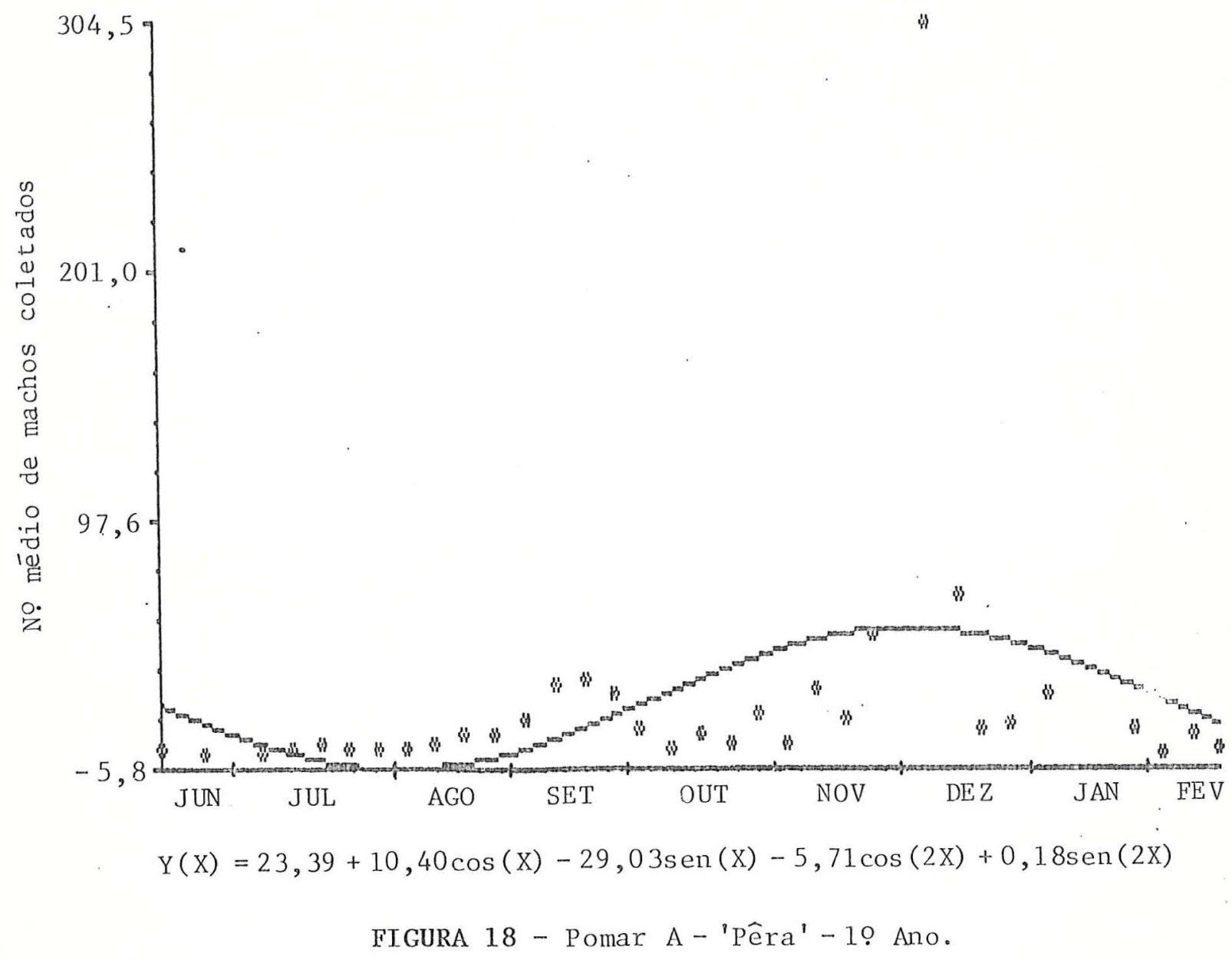

TABELA 27 - Anālise de variância para variedade 'Pêra' - 10 Ano - Pomar A.

\begin{tabular}{lcccc}
\hline Fontes de Variação & G.L. & S.Q. & Q.M. & F \\
\hline Regr. H. 19 Grau & 2 & 13276,08 & 6638,04 & $2,61^{\text {NS }}$ \\
Desvio Regr. H. 19 Grau & 30 & 76192,06 & 2539,74 & - \\
\hline Ad. Regr. H. 20 Grau & 2 & 8686,22 & 4343,11 & $1,80^{\text {NS }}$ \\
Desvio Regr. H. 29 Grau & 28 & 67505,84 & 2410,92 & - \\
\hline
\end{tabular}




\subsection{Correlaģäo coñ Dados Climáticos}

As correlações entre nümero médio de machos coletados e fa tores climáticos em cada variedade para o mês corrente, mês anterior e o quinto anterior, resultaram valores não significativos, aos níveis de signi ficância considerados, o que evidencia, do ponto de vista estatístico, uma relação não linear entre esses parâmetros.

0 nümero mëdio de machos capturados na variedade 'Ponkan' não correlacionou-se com nenhum dos fatores meteorológicos considerados.

Dentre os fatores meteorológicos analisados, as temperaturas médias, máxima e mínima de dois, três e quatro meses antes foram as que me lhores correlacionaram com o nümero médio de machos coletados. Os valores negativos dos coeficientes de correlação explicam um possível declínio na população com o aumento das referidas temperaturas.

Para a maioria das variedades, a variação da temperatura de dois meses antes está também correlacionada com o nümero médio de machos co letados da praga. Os valores positivos dos coeficientes de correlação expli cam a contribuição no aumento da população com o aumento da variação da tem peratura.

Finalmente, a precipitação pluviométrica de dois, três e quatro meses antes está razoavelmente corrélacionada com o nümero médio de machos coletados da praga. Os valores negativos dos coeficientes de correla ção explicam a contribuição desse fator climätico na diminuição da popula ção.

Os resultados destas correlações encontram-se nas Tabelas 27 e 28. 
TABELA 27 - Pomar A - Valores dos coeficientes de correlação entre número médio de machos coletados mensalmente (em cada variedade) e fatores climáticos.

\begin{tabular}{|c|c|c|c|c|c|c|}
\hline Variedace & Períoio & $\begin{array}{c}\text { Temp. maxima } \\
\text { noviaimes }\end{array}$ & $\begin{array}{c}\text { Teno minima } \\
\text { ñdialmos }\end{array}$ & $\begin{array}{l}\text { Variacúo } \\
\text { zcm / / Mus }\end{array}$ & $\begin{array}{l}\text { Pṛecipitação } \\
\text { média/mes }\end{array}$ & $\begin{array}{l}\text { Und. Rel. } \\
\text { midilmes }\end{array}$ \\
\hline Ponkan & $\begin{array}{l}\text { mès corrente } \\
1 \text { mes ant. } \\
2 \text { meses ant. } \\
3 \text { meses ant. } \\
4 \text { meses ant. } \\
5 \text { meses ant. }\end{array}$ & $\begin{array}{l}-0,17 \\
-0,56 x \\
-0,31 \\
-0,11 \\
0,20 \\
0,33\end{array}$ & $\begin{array}{l}-0,17 \\
-0,20 \\
0,03 \\
0,09 \\
0,30 \\
0,40 \div\end{array}$ & $\begin{array}{l}0,11 \\
-0,22 \\
-0,3 i \\
-0,23 \\
-0,32 \\
-0,47+\end{array}$ & $\begin{array}{r}-0,40 \\
-0,07 \\
0,13 \\
-0,09 \\
-0,16 \\
-0,05\end{array}$ & $\begin{array}{c}-0,42 \\
0,23 \\
0,41+ \\
0,47 \\
0,30 \\
0,26\end{array}$ \\
\hline Natal & $\begin{array}{l}\text { més corrente } \\
1 \text { nes ant. } \\
2 \text { meses ant. } \\
3 \text { meses ant. } \\
4 \text { meses ant. } \\
5 \text { meses art. }\end{array}$ & $\begin{array}{l}0,15 \\
-0,22 \\
-0,57 * \\
-0,72 * \% \\
-0,54 \% \\
-0, ? 4\end{array}$ & $\begin{array}{l}0,05 \\
-0,37 \\
-0,6,3 * * \\
-0,61 * \\
-0,28 \\
-0,20\end{array}$ & $\begin{array}{l}0,07 \\
0,33 \\
0,41 \div \\
0,36 \\
-0,01 \\
0,04\end{array}$ & $\begin{array}{l}0,22 \\
-0,22 \\
-0,45+ \\
-0,44+ \\
-0,17 \\
-0,24\end{array}$ & $\begin{array}{r}-0,23 \\
-0,32 \\
0,02 \\
0,14 \\
0,47 \\
0,19\end{array}$ \\
\hline Murcote & $\begin{array}{l}\text { més corrente } \\
1 \text { mess ant. } \\
2 \text { meses ant. } \\
3 \text { meses ant. } \\
4 \text { meses ant. } \\
5 \text { meses ant. }\end{array}$ & $\begin{array}{l}0,27 \\
-0,02 \\
-0,41 \div \\
-0,79 * \% \\
-0,79 \times x \\
-0,49+\end{array}$ & $\begin{array}{l}0,12 \\
-0,28 \\
-0,63 * x \\
-0,52 * \% \\
-0,62 * \\
-0,3 i\end{array}$ & $\begin{array}{l}0, .06 \\
0,38 \\
2,56 x \\
0.454 \\
0,34 \\
0,12\end{array}$ & $\begin{array}{l}0,25 \\
-0,09 \\
-0,54 * \\
-0,43+ \\
-0,35 \\
-0,21\end{array}$ & $\begin{array}{l}-0,20 \\
-0,47 x \\
-0,30 \\
0,16 \\
0,27 \\
0,24\end{array}$ \\
\hline Valência & $\begin{array}{l}\text { més coriente } \\
1 \text { mes ant. } \\
2 \text { meses ant. } \\
3 \text { icses ant. } \\
4 \text { meses ant. } \\
5 \text { meses ant. }\end{array}$ & $\begin{array}{l}0,14 \\
-0,11 \\
-0,67 * x \\
-0,83 * \% \\
-0,67 \div \% \\
-0,17\end{array}$ & $\begin{array}{l}0,12 \\
-0,26 \\
-0,85 \div \% \\
-0,71 \% \\
-0,55 x \\
-0,10\end{array}$ & $\begin{array}{l}-0.05 \\
0,23 \\
0,65 \% \\
0.41 \\
0.32 \\
0.02\end{array}$ & $\begin{array}{l}0,21 \\
-0,09 \\
-0,51 \% \\
-0,38 \\
-0,44 \% \\
-0,16\end{array}$ & $\begin{array}{r}-0,25 \\
-0,31 \\
-0,16 \\
0,07 \\
0,26 \\
0,25\end{array}$ \\
\hline Pera & $\begin{array}{l}\text { mes corrente } \\
1 \text { mes ant. } \\
2 \text { meses ant. } \\
3 \text { moses ant. } \\
4 \text { meses ant. } \\
5 \text { moses ant. }\end{array}$ & $\begin{array}{l}0,15 \\
0,07 \\
-0,41 \div \\
-0,70 \% \\
-0,55 \% \\
-0,16\end{array}$ & $\begin{array}{l}0,15 \\
0,02 \\
-0,57 \% \\
-0,73 \% \\
-0,34 \\
-0,14\end{array}$ & $\begin{array}{c}-0,09 \\
0,05 \\
0,37 \\
0,56 \% \\
0,09 \\
0,03\end{array}$ & $\begin{array}{l}0,26 \\
0,14 \\
-0,26 \\
-0,50 * \\
-0,00 \\
-0,17\end{array}$ & $\begin{array}{r}-0,13 \\
-0,23 \\
-0,04 \\
-0,00 \\
0,19 \\
0,29\end{array}$ \\
\hline
\end{tabular}

xit Significativo a ir $\quad+$ Significativo a $10 \%$

$\therefore$ Significazivo a $5 \%$ 
TABELA 28 - Pomar B - Valores dos coeficientes de correlação entre número médio de machos coletados mensal mente (em cada variedade) e fatores climáticos.

\begin{tabular}{|c|c|c|c|c|c|c|}
\hline Variedade & Período & $\begin{array}{l}\text { Temp. máxima } \\
\text { média/mês }\end{array}$ & $\begin{array}{l}\text { Temp. minima } \\
\text { média/mês }\end{array}$ & $\begin{array}{l}\text { Variação } \\
\text { Temp./mês }\end{array}$ & $\begin{array}{c}\text { Precipitação } \\
\text { média/mês }\end{array}$ & $\begin{array}{l}\text { Umid. Rel. } \\
\text { média/mês }\end{array}$ \\
\hline Pera & $\begin{array}{l}\text { més corrente } \\
1 \text { mês ant. } \\
2 \text { meses ant. } \\
3 \text { meses ant. } \\
4 \text { meses ant. } \\
5 \text { meses ant. }\end{array}$ & $\begin{array}{l}0,20 \\
0,11 \\
-0,20 \\
-0,82 * * \\
-0,64 * * \\
-0,17\end{array}$ & $\begin{array}{l}0,17 \\
0,09 \\
-0,27 \\
-0,75 * * \\
-0,52 * \\
-0,04\end{array}$ & $\begin{array}{c}-0,08 \\
-0,03 \\
0,22 \\
0,49 * \\
0,31 \\
-0,09\end{array}$ & $\begin{array}{r}0,33 \\
0,22 \\
-0,05 \\
-0,41 \\
-0,36 \\
-0,08\end{array}$ & $\begin{array}{r}-0,16 \\
-0,21 \\
-0,20 \\
0,05 \\
0,05 \\
0,35\end{array}$ \\
\hline Piralima & $\begin{array}{l}\text { mês corrente } \\
1 \text { mês ant. } \\
2 \text { meses ant. } \\
3 \text { meses ant. } \\
4 \text { meses ant. } \\
5 \text { meses ant. }\end{array}$ & $\begin{array}{l}0,14 \\
0,01 \\
-0,45+ \\
-0,58 * \\
-0,36 \\
-0,01\end{array}$ & $\begin{array}{c}0,14 \\
-0,04 \\
-0,35 \\
-0,54 * \\
-0,31 \\
0,11\end{array}$ & $\begin{array}{r}-0,08 \\
0,07 \\
0,12 \\
0,36 \\
0,19 \\
-0,19\end{array}$ & $\begin{array}{r}0,24 \\
0,07 \\
-0,05 \\
-0,30 \\
-0,17 \\
-0,06\end{array}$ & $\begin{array}{r}-0,13 \\
-0,21 \\
0,26 \\
0,14 \\
-0,18 \\
0,26\end{array}$ \\
\hline Cravo & $\begin{array}{l}\text { mes corrente } \\
1 \text { mes ant. } \\
2 \text { meses ant. } \\
3 \text { meses ant. } \\
4 \text { meses ant. } \\
5 \text { meses ant. }\end{array}$ & $\begin{array}{l}0,14 \\
0,09 \\
-0,33 \\
-0,51 * \\
-0,52 * \\
-0,33\end{array}$ & $\begin{array}{l}0,15 \\
0,01 \\
-0,47 * \\
-0,50 * \\
-0,25 \\
-0,33\end{array}$ & $\begin{array}{r}-0,09 \\
0,07 \\
0,39 \\
0,36 \\
-0,04 \\
0,26\end{array}$ & $\begin{array}{l}0,23 \\
0,05 \\
-0,43+ \\
-0,40 \\
-0,01 \\
-0,27\end{array}$ & $\begin{array}{r}-0,11 \\
-0,26 \\
-0,10 \\
-0,03 \\
0,49 \\
0,11\end{array}$ \\
\hline Murcote & $\begin{array}{l}\text { més corrente } \\
1 \text { mes ant. } \\
2 \text { meses ant. } \\
3 \text { meses ant. } \\
4 \text { meses ant. } \\
5 \text { meses ant. }\end{array}$ & $\begin{array}{l}0,14 \\
-0,25 \\
-0,44+ \\
-0,65 * * \\
-0,61 * \\
-0,37\end{array}$ & $\begin{array}{l}0,12 \\
-0,49 * \\
-0,56 * \\
-0,58 * \\
-0,36 \\
-0,27\end{array}$ & $\begin{array}{c}-0,06 \\
0,49 * \\
0,43+ \\
0,37 \\
0,06 \\
0,12\end{array}$ & $\begin{array}{l}0,19 \\
-0,46 * \\
-0,50 * \\
-0,48 \\
-0,20 \\
-0,27\end{array}$ & $\begin{array}{r}-0,15 \\
-0,36 \\
-0,09 \\
0,13 \\
0,47 \\
0,23\end{array}$ \\
\hline
\end{tabular}

$* *$ Significativo a $1 \%$

* Significativo a $5 \%$ 


\section{CONCLUSÕES}

A partir das anālises efetuadas pode-se chegar as seguintes conclusões:

- o modelo de regressão harmônica explica razoavelmente a evolução da praga $C$. capitata nos dois pomares estuda dos;

- é possível prever para cada variedade após quantos dias do início do ciclo de infestação se dá predominantemente a quantidade máxima de insetos no campo;

- houve um razoável ajuste à distribuição binomial negativa, mas com $k$ comum variando por semana e variedade.

- os modelos de Iwao e binomial negativa com $k$ comum são su periores ao modelo de Taylor preferindo-se o modelo bino mial negativa por ter somente um parâmetro;

- houve correlação negativa entre a captura dos machos e as temperaturas mäxima e minima ocorridas a dois, três e qua tro meses antes das capturas;

- houve correlação positiva entre a captura dos machos e a variação de temperatura ocorrida dois meses antes das cap turas;

- houve correlação negativa entre a captura dos machos oom a precipitação pluviométrica ocorrida a dois, três e qua tro meses antes das capturas;

- não houve correlação entre umidade relativa e captura dos machos. 


\section{LTTERATURA CITADA}

BARBOSA, J.C. Distribuições de probabilidade como base para análises esta tisticas, amostragens estratégicas de manejo de Diatraea saccharalis (Fabr., 1794) na cultura de cana-de-acücar. Piracicaba, ESALQ-USP, 1985. p.VIII. (Tese de doutoramento).

BLISS, C.I. Periodic regression in biology and climatology. New Haven, Connecticut, Agr. Exp. Stat., 1958. (Bo1., 615).

BLISS, C.I. Estatistics in biology. New York, McGraw-Hi11. Book, 1970. V. 2, 219-287.

BORATTO, F. Basic para engenheiros e cientístas. 2aㅡ ed. Rio de Janeiro. Livros Técnicos e Cientïficos, 1984. 108 p.

DUARTE, G.S. O emprego da anälise harmônica no estudo da incidência da ferrugem alaranjada do cafeeiro (Hemileia vastatrix Berk et Br.) no Esta do de Minas Gerais. Piracicaba, ESALQ-USP, 1981. 46 p. (Tese de douto ramento).

DUARTE, G.S.; SILVEIRA, J.V.; VEIGA, R.D. Determinação de um modelo mate mätico para previsão da incidêneia da ferrugem do cafeeiro (Hemileia vas tratix Berk et Br.). Campinas, Fundação Cargi1, 1985. 44 p.

ELLIOT, N.C. \& KIECKHEFER, R.W. Spatial distributions of cereal aphids (Homoptera: Aphididae) in winter wheat and spring oats in South Dakota. Environ. Entomol., 16:896-901, 1987.

EVANS, D.E. Experimental evidence concerning contagions distributions in ecology. Biometrika, 40:186-211, 1953.

FELTRIN, M.A.V. A anälise harmônica no estudo das precipitações pluviais no municipio de Bandeirantes (PR). Piracicaba, ESALQ-USP, 1980. p.8183. (Dissertação de mestrado). 
FERNANDES, A.O. Estudos bioecolögicos e avaliação de danos causados por moscas-das-frutas (Diptera: Tephritidae) em citrus sinensis OSBECK var. PÊRA. Ribeirão Preto, USP, 1987. 53 p. (Dissertação de mestrado). GAHUKAR, R.T. Population dynamics of sorghum shoot fly, atherigona socca ta (Diptera: Muscidae), in Senega1. Environ. Entomol., 16(4):910-916, 1987.

GALlO, D.; NAKANO, O.; WIENDL, F.M.; SILVEIRA NETO, S.; CARVALHO, R.P.L. Manual de Entomologia. São Paulo, Agronômica Ceres, 1970. 860 p.

IAEA. Breeding for eradication: medfly campaign in Japan. Vienna, Aus tria. Buzletin, 29(2):18-19, 1987.

KAMBUROV, S.S.; YAWETZ, A.; NADEL, D.J. Application of the sterile--insect technique for control of mediterranean fruit flies in Israel under field conditions. In: STERILITY PRINCIPLE FOR INSECT CONTROL OR ERADICATION, Viena, 1975. IAEA. p. 67-76.

KNIPLING, E.F. Present status and future trends of the sit approach to the control of arthropod pests. In: STERILE INSECT TECHNIQUE AND RADIATION IN INSECT CONTROL, Viena, 1982. IAEA. p. 3-23.

LABRECQUE, G. Helping eradicate the medfly from Mexico. IAEA-Bulzetin, ( $\sup 1.): 26-29,1982$.

LARA, F.M. Influência de fatores ecológicos na coleta de algumas pragas com armadithas Zuminosas. Piracicaba, ESALQ-USP, 1974. p.114-115. (Dis sertação de mestrado).

LINDQUIST, A. Insects, isotopes, and radiation. IAEA-Bulletin, 29(2):9$12,1987$.

LITTLE, T.M. \& HILLS, F.I. Statistical methods in agricultural research. 2- ed. Davis, University of California, 1975. 242 p.

MELLAdO, L. Técnica de machos esteriles en el control de la mosca del me diterraneo. Programas realizados en España. In: STERILITY PRINCIPLE OF INSECT CONTROL OR ERADICATION, Viena, 1971. IAEA. p. 49-54.

NOWIERSKI, R.M.; STORY, J.M.; LUND, R.E. Two-level numerical samp1ing plans and optimal subsample size computation for urophora affinis and uro phora quadrifasciata (Diptera: Tephritidae) ou spotted knapweed. Envi ron. Entomol., 16(4):933-937, 1987.

ORLANDO, A. \& SAMPAIO, A.S. "Moscas-das-frutas": Notas sobre reconhecimen to e combate. O Biolögico, 39:143-150, 1973. 
PARRA, J.R.P.; ZUCCHI, R.A.; SILVEIRA NETO, S. F1utuação populacional e atividade diäria de vôo da mosca-do-mediterrâneo em cafeeiros Mundo Novo. Pesq. Agropec. bras., Brasĩlia, 17(7):985-992, 1982.

PATTON, P. Programa contra la mosca del mediterraneo en Mexico. In: STERI LE INSECT TECHNIQUE AND RADIATION IN INSECT CONTROL, Viena. IAEA. p. 2537,1982 .

PERECIN, D. Distribuições binomiais negativas com expoente $k$ comm e algu mas aplicacões em Pedologia e Entomologia. Jaboticabal, FCAV-UNESP, 1978. 129 p. (Tese de livre-docente).

PIELOU, E.C. Spatial patterns in one-species populations. In: Mathemati cal Ecology. New York, John Wiley, 1977. p. 113-134.

PIETERS, E.P. \& STERLING, W, L. Inferences on the disperson of cotton arth ropods in Texas. Environ. Entomol., 2:863--867, 1973.

PUZZI, D. \& ORLANDO, A. Estudos sobre a ecologia das "moscas-das-frutas"

(Tephritidae) no Estado de São Paulo, visando o controle racional da pra ga. Arq. Inst. Biol., São Paulo, 32(1):9-2.2, 1965.

QUINTERos, H.O. Determinação de uma distribuição estatistica adequada a dados de contagem de lagartas de Scrobipalpula absoluta (Meyrick), em to mate (Lycopersicum esculentum, MilZ), e um plano de amostragem apropria do. Piracicaba, ESALQ-USP, 1984. 92 p. (Dissertação de mestrado).

RHODE, R.H.; SIMON, J•; PERDOMO, A.; GUTIERREZ, J•; DOWLING JR., C.F.; LIND QUIST, D.A. Application of the sterile-insect release technique in medi terranean fruit suppression. J. Econ. Entomol., 64(3):708-713, 1971.

SALIFU, A.B. \& HODGSON, C.J. Dispersion patterns and sequential sampling plaus for megalurothrips sjostedti (Trybom) (Thysanaptera: Thripidae) in cowpear. Bull. Ent. Res., 77:441-449, 1987.

SEVACHERIAN, V. \& STERN, V.M. Spatial distribution patterns of hygus bugs in California cotton fields. Environ. Entomol., 1:695-704, 1972.

SGRILLO, R.B.; WIENDL, F.M.; PACHECO, J.M.; WALDER, J.M.M.; DOMARCO, R.E. A técnica do macho estëril. Piracicaba, CENA, 1974. 25 p. (Publicação especial).

SHEPARD, M. Spatial patterns and over crowding, of the bean leaf roller, urbanus protens (Lepidoptera: Hesperïdae). Ann. Entomol. Soc. Amer., 95: $1124-1125,1972$. 
SILVEIRA NETO, S. Flutuação da população e controle das principais pragas da familia Pyraustidae com emprego de armadithas Zuminosas. Piracicaba, ESALQ-USP, 1969. p. 76. (Tese de doutoramento).

SILVEIRA NETO, S. Levantamento de insetos e flutuação da populaça de pra gas da ordem Lepidöptera, com o uso de armadithas Iuminosas em diversas regiões do Estado de São Paulo. Piracicaba, ESALQ-USP, 1972. p. 158-159. (Tese de livre-docente).

SUPLICY FILHO, N.; SAMPAIO, A.S.; MYASAKI, I. Flutuação populacional das moscas-das-frutas (Anastrepha spp. e Ceratitis capitata (Wied., 1824) em citros na Fazenda Guanabara, Barretos (SP). O Biolögico, 44:279-284, 1978. TAYLOR, R.A.J. Time series analysis of numbers of lepidoptera caught at light traps in East Africa, and the effect of moonlight on trap efficien cy. Bulz. Entomol. Res., 76:593-606, 1986.

THIÉBAUT, J.T.L. O emprego da anälise harmônica no estudo das precipita gões mensais no municipio de Vicosa (MG). Piracicaba, ESALQ-USP, 1976. p. 82-83. (Dissertação de mestrado).

VARGAS, R.I.; HARRIS, E.J.; NISHIDA, T. Distribution and seasonal accur rence of Ceratitis capitata (Wiedemann) (Diptera: Tephritidae) on the is 1 and of Kanai in the Hawaüan islands. Environ. Entomol., 12(2):303-310, 1982 .

WALDER, M.M.J. Uso das técnicas nucleares no estudo e controle da moscado-mediterrâneo, Ceratitis capitata (Wied., 1824)(Diptera: Tephritidae). Piracicaba (SP). CNPq, 1983. 28 p. (Relatório de atividades).

WATERS, W.E. \& HENSON, W.R. Some sampling attributes of the negative bi nomial distribution with special reference to forest insects. For. Sci., 5: 397-412, 1959 .

YUEN-SHAUNG, N.G.; TROUT, J.R.; AHMAO, S. Spatial distribution of the 1 ar val population of the japanese beetle (Coleoptera: Scarabaeidae) in Turf grass. J. Econ. Entomol., 76:26-30, 1983. 
APENDICE 1 - Nümero médio de machos coletados por armadilha e por varie dade, no período de 09/06/80 a 19/02/81 (Pomar A - 19 ano).

\begin{tabular}{|c|c|c|c|c|c|c|}
\hline \multirow{2}{*}{$\begin{array}{c}\text { Dias } \\
\text { acumulados }\end{array}$} & \multirow{2}{*}{ Data } & \multicolumn{5}{|c|}{ Variedade } \\
\hline & & Ponkan & Nata1 & Murcote & Va1ência & Pêra \\
\hline 10 & $09 / 06 / 80$ & 12,0 & 4,0 & 3,5 & 2,6 & 2,0 \\
\hline 20 & $19 / 06 / 80$ & - & 4,0 & 5,5 & 1,0 & 1,0 \\
\hline 34 & $03 / 07 / 80$ & 22,0 & 4,0 & 4,5 & 2,6 & 0,5 \\
\hline 41 & $10 / 07 / 80$ & 7,0 & 1,3 & 3,0 & 0,8 & 1,5 \\
\hline 48 & $17 / 07 / 80$ & 22,0 & 1,7 & 3,5 & 1,4 & 3,5 \\
\hline 55 & $24 / 07 / 80$ & 49,0 & 4,0 & 5,0 & 2,6 & 1,5 \\
\hline 62 & $31 / 07 / 80$ & 110,0 & 8,0 & 15,5 & 4,6 & 2,5 \\
\hline 69 & $07 / 08 / 80$ & 58,0 & 8,0 & 7,5 & 3,2 & 2,0 \\
\hline 76 & $14 / 08 / 80$ & 46,0 & 6,0 & 8,5 & 3,4 & 4,0 \\
\hline 83 & $21 / 08 / 80$ & 35,0 & 5,0 & 9,0 & 4,0 & 8,0 \\
\hline 90 & $28 / 08 / 80$ & 39,0 & 6,0 & 12,0 & 3,4 & 9,5 \\
\hline 97 & $04 / 09 / 80$ & 32,0 & 3,7 & 12,5 & 3,0 & 15,0 \\
\hline 105 & $12 / 09 / 80$ & 24,0 & 10,0 & 27,0 & 5,4 & 28,5 \\
\hline 112 & $19 / 09 / 80$ & 1,0 & 8,0 & 57,0 & 7,6 & 30,5 \\
\hline 119 & $26 / 09 / 80$ & 3,0 & 8,3 & 41,5 & 8,2 & 25,5 \\
\hline 125 & $02 / 10 / 80$ & 6,0 & 8,3 & 68,5 & 6,6 & 10,5 \\
\hline 132 & $09 / 10 / 80$ & 28,0 & 35,0 & 113,5 & 6,4 & 2,5 \\
\hline 139 & $16 / 10 / 80$ & 18,0 & 15,0 & 186,0 & 4,6 & 9,5 \\
\hline 146 & $23 / 10 / 80$ & 32,0 & 13,3 & 150,0 & 7,0 & 5,5 \\
\hline 153 & $30 / 10 / 80$ & 20,0 & 7,7 & 500,0 & 6,4 & 16,0 \\
\hline 160 & $06 / 11 / 80$ & 7,0 & 6,7 & 272,5 & 7,6 & 4,5 \\
\hline 167 & $13 / 11 / 80$ & 31,0 & 13,7 & 189,5 & 11,4 & 27,5 \\
\hline 174 & $20 / 11 / 80$ & 2,0 & 1,0 & 53,5 & 4,6 & 14,0 \\
\hline 181 & $27 / 11 / 80$ & 3,0 & 3,0 & 26,0 & 13,8 & 50,0 \\
\hline 195 & $11 / 12 / 80$ & 2,0 & 4,0 & 60,5 & 37,4 & 304,5 \\
\hline 202 & $18 / 12 / 80$ & 6,0 & 6,3 & 9,5 & 20,0 & 67,5 \\
\hline 207 & $23 / 12 / 80$ & 8,0 & 2,3 & 3,0 & 7,2 & 11,0 \\
\hline 214 & $30 / 12 / 80$ & 4,0 & 3,0 & 3,0 & 3,8 & 13,0 \\
\hline 223 & $08 / 01 / 81$ & 3,0 & 0,7 & 2,5 & 5,8 & 26,0 \\
\hline 244 & $29 / 01 / 81$ & 2,0 & 3,7 & 3,0 & 9,0 & 11,5 \\
\hline 251 & $05 / 02 / 81$ & 0,0 & 0,0 & 0,0 & 1,0 & 1,0 \\
\hline 259 & $13 / 02 / 81$ & 0,0 & 1,0 & 0,0 & 0,6 & 8,5 \\
\hline 265 & $19 / 02 / 81$ & 0,0 & 1,0 & 0,0 & 0,0 & 3,0 \\
\hline
\end{tabular}


APÊNDICE 2 - Nümero mëdio de machos coletados por armadilha e por varie dade, no período de 11/06/81 a 18/02/82 (Pomar A - 20 ano).

\begin{tabular}{|c|c|c|c|c|c|c|}
\hline \multirow{2}{*}{$\begin{array}{c}\text { Dias } \\
\text { acumulados }\end{array}$} & \multirow{2}{*}{ Data } & \multicolumn{5}{|c|}{ Variedade } \\
\hline & & Ponkan & Nata1 & Murcote & Valência & Pêra \\
\hline 7 & $11 / 06 / 81$ & 0,0 & 0,3 & 1,0 & 0,6 & 0,3 \\
\hline 21 & $25 / 06 / 81$ & 3,0 & 4,3 & 13,5 & 5,2 & 5,0 \\
\hline 28 & $02 / 07 / 81$ & 7,0 & 2,7 & 6,5 & 10,6 & 5,7 \\
\hline 35 & $09 / 07 / 81$ & 0,0 & 4,0 & 5,5 & 4,0 & 3,3 \\
\hline 42 & $16 / 07 / 81$ & 0,0 & 6,7 & 4,0 & 6,4 & 4,0 \\
\hline 50 & $24 / 07 / 81$ & 8,0 & 16,0 & 17,0 & 11,6 & 12,7 \\
\hline 56 & $30 / 07 / 81$ & 9,0 & 12,3 & 20,0 & 6,6 & 6,7 \\
\hline 63 & $06 / 08 / 81$ & 10,0 & 4,0 & 26,0 & 5,0 & 10,0 \\
\hline 70 & $13 / 08 / 81$ & 21,0 & 4,3 & 30,5 & 7,6 & 7,0 \\
\hline 77 & $20 / 08 / 81$ & 40,0 & 6,7 & 25,5 & 5,0 & 6,0 \\
\hline 84 & $27 / 08 / 81$ & 29,0 & 4,7 & 34,0 & 6,6 & 14,7 \\
\hline 91 & $03 / 09 / 81$ & 40,0 & 24,3 & 30,0 & 22,6 & 52,0 \\
\hline 98 & $10 / 09 / 81$ & 35,0 & 26,0 & 192,5 & 59,4 & 103,7 \\
\hline 105 & $17 / 09 / 81$ & 12,0 & 27,3 & 176,0 & 90,8 & 116,3 \\
\hline 110 & $22 / 09 / 81$ & 4,0 & 26,0 & 108,5 & 69,6 & 60,7 \\
\hline 119 & $01 / 10 / 81$ & 4,0 & 36,7 & 98,5 & 129,2 & 87,0 \\
\hline 126 & $08 / 10 / 81$ & 3,0 & 8,7 & 22,5 & 35,0 & 63,3 \\
\hline 133 & $15 / 10 / 81$ & 0,0 & 9,0 & 29,0 & 24,0 & 86,3 \\
\hline 141 & $23 / 10 / 81$ & 3,0 & 13,7 & 57,5 & 46,8 & 88,3 \\
\hline 147 & $29 / 10 / 81$ & 3,0 & 3,7 & 22,0 & 18,4 & 21,3 \\
\hline 154 & $05 / 11 / 81$ & 3,0 & 7,0 & 48,0 & 33,4 & 71,7 \\
\hline 161 & $12 / 11 / 81$ & 3,0 & 2,3 & 13,0 & 29,2 & 33,7 \\
\hline 175 & $26 / 11 / 81$ & 8,0 & 7,0 & 35,5 & 34,6 & 29,0 \\
\hline 182 & $03 / 12 / 81$ & 0,0 & 7,7 & 9,5 & 13,4 & 21,7 \\
\hline 189 & $10 / 12 / 81$ & 2,0 & 7,3 & 13,0 & 9,6 & 21,7 \\
\hline 196 & $17 / 12 / 81$ & 0,0 & 5,3 & 5,5 & 6,4 & 13,7 \\
\hline 201 & $22 / 12 / 81$ & 1,0 & 0,3 & 14,0 & 4,8 & 13,7 \\
\hline 209 & $30 / 12 / 81$ & 0,0 & 0,3 & 16,0 & 6,4 & 18,7 \\
\hline 217 & $07 / 01 / 82$ & 1,0 & 2,0 & 7,5 & 2,2 & 8,7 \\
\hline 224 & $14 / 01 / 82$ & 1,0 & 1,0 & 1,5 & 0,8 & 1,0 \\
\hline 231 & $21 / 01 / 82$ & 1,0 & 1,0 & 9,0 & 0,2 & 2,3 \\
\hline 238 & $28 / 01 / 82$ & 1,0 & 0,7 & 1,5 & 0,4 & 2,3 \\
\hline 245 & $04 / 02 / 82$ & 0,0 & 0,0 & 3,5 & 0,2 & 0,7 \\
\hline 259 & $11 / 02 / 82$ & 0,0 & 0,3 & 1,5 & 0,0 & 0,7 \\
\hline 267 & $18 / 02 / 82$ & 0,0 & 0,3 & 3,0 & 0,0 & 0,3 \\
\hline
\end{tabular}


APÊNDICE 3 - Nümero médio de machos coletados por armadilha e por varie dade, no período de 01/07/82 a 22/12/82 (Pomar A - 30 ano).

\begin{tabular}{ccccccc}
\hline \multirow{2}{*}{$\begin{array}{c}\text { Dias } \\
\text { acumulados }\end{array}$} & Data & \multicolumn{5}{c}{ Variedade } \\
\cline { 3 - 6 } & & Ponkan & Natal & Murcote & Va1ência & Pêra \\
\hline 12 & $01 / 07 / 82$ & 0,0 & 0,3 & 0,5 & 0,4 & 0,3 \\
19 & $08 / 07 / 82$ & 0,0 & 0,3 & 0,0 & 0,2 & 0,0 \\
26 & $15 / 07 / 82$ & 1,0 & 0,0 & 0,0 & 0,2 & 0,0 \\
33 & $22 / 07 / 82$ & 0,0 & 1,3 & 1,0 & 0,6 & 0,7 \\
39 & $28 / 07 / 82$ & 1,0 & 0,0 & 0,5 & 0,0 & 0,0 \\
46 & $05 / 08 / 82$ & 5,0 & 1,0 & 1,5 & 0,6 & 0,0 \\
53 & $12 / 08 / 82$ & 1,0 & 0,0 & 2,5 & 0,2 & 1,0 \\
60 & $19 / 08 / 82$ & 3,0 & 1,0 & 0,5 & 0,0 & 0,0 \\
67 & $26 / 08 / 82$ & 2,0 & 0,0 & 1,0 & 0,2 & 1,3 \\
74 & $02 / 09 / 82$ & 1,0 & 0,3 & 0,5 & 0,4 & 0,3 \\
81 & $09 / 09 / 82$ & 0,0 & 0,0 & 0,5 & 0,0 & 0,3 \\
88 & $16 / 09 / 82$ & 0,0 & 0,0 & 2,5 & 1,0 & 0,0 \\
95 & $23 / 09 / 82$ & 1,0 & 0,7 & 4,0 & 0,2 & 0,0 \\
102 & $30 / 09 / 82$ & 3,0 & 1,0 & 5,0 & 0,4 & 0,0 \\
116 & $14 / 10 / 82$ & 1,0 & 1,3 & 7,0 & 0,4 & 0,3 \\
123 & $21 / 10 / 82$ & 0,0 & 1,0 & 1,0 & 0,2 & 0,7 \\
131 & $29 / 10 / 82$ & 4,0 & 1,7 & 4,0 & 0,2 & 1,3 \\
137 & $04 / 11 / 82$ & 1,0 & 0,3 & 2,0 & 0,4 & 0,0 \\
145 & $12 / 11 / 82$ & 0,0 & 0,0 & 7,0 & 0,4 & 0,3 \\
151 & $18 / 11 / 82$ & 0,0 & 0,3 & 0,0 & 0,0 & 0,0 \\
158 & $25 / 11 / 82$ & 0,0 & 0,0 & 0,0 & 0,4 & 0,0 \\
165 & $02 / 12 / 82$ & 0,0 & 0,0 & 0,0 & 0,4 & 0,0 \\
185 & $22 / 12 / 82$ & 0,0 & 0,0 & 0,0 & 0,0 & 0,0 \\
\hline
\end{tabular}


APENDICE 4 - Nümero mëdio de machos coletados por armadilha e por varie dade, no período de 14/07/83 a 02/12/83 (Pomar A - 49 ano).

\begin{tabular}{ccccccc}
\hline \multirow{2}{*}{$\begin{array}{c}\text { Dias } \\
\text { acumulados }\end{array}$} & Data & \multicolumn{5}{c}{ Variedade } \\
\cline { 3 - 6 } & & Ponkan & Natal & Murcote & Valéncia & Pêra \\
\hline 28 & $14 / 07 / 83$ & 56,0 & 1,3 & 0,0 & 0,0 & 0,3 \\
42 & $28 / 07 / 83$ & 6,0 & 0,7 & 3,0 & 0,2 & 0,0 \\
63 & $18 / 08 / 83$ & 12,0 & 0,7 & 2,5 & 0,8 & 0,0 \\
76 & $01 / 09 / 83$ & 22,0 & 0,7 & 1,0 & 0,4 & 0,0 \\
97 & $22 / 09 / 83$ & 5,0 & 4,3 & 40,0 & 4,0 & 0,0 \\
111 & $06 / 10 / 83$ & 4,0 & 1,7 & 0,0 & 1,6 & 0,7 \\
125 & $20 / 10 / 83$ & 3,0 & 2,0 & 4,0 & 2,5 & 1,5 \\
139 & $03 / 11 / 83$ & 6,0 & 2,0 & 6,0 & 1,8 & 2,5 \\
154 & $18 / 11 / 83$ & 0,0 & 3,7 & 16,0 & 5,3 & 9,0 \\
168 & $02 / 12 / 83$ & 1,0 & 0,7 & 6,5 & 5,6 & 3,0 \\
\hline
\end{tabular}


APÊNDICE 5 - Nümero médio de machos coletados por armadilha e por varie dade, no periodo de 10/07/80 a 13/03/81 (Pomar B - 10 ano).

\begin{tabular}{|c|c|c|c|c|c|}
\hline \multirow{2}{*}{$\begin{array}{c}\text { Dias } \\
\text { acumulados }\end{array}$} & \multirow{2}{*}{ Data } & \multicolumn{4}{|c|}{ Variedade } \\
\hline & & Pêra & Piralima & Cravo & Murcote \\
\hline 7 & $10 / 07 / 80$ & 3,8 & 0,0 & 0,0 & 10,0 \\
\hline 14 & $17 / 07 / 80$ & 5,8 & 0,0 & 0,0 & 8,0 \\
\hline 21 & $24 / 07 / 80$ & 8,0 & 0,0 & 0,0 & 9,0 \\
\hline 28 & $31 / 07 / 80$ & 15,0 & 2,5 & 0,0 & 28,0 \\
\hline 35 & $07 / 08 / 80$ & 8,5 & 1,0 & 0,0 & 16,0 \\
\hline 42 & $14 / 08 / 80$ & 14,8 & 2,0 & 2,5 & 4,0 \\
\hline 49 & $21 / 08 / 80$ & 16,0 & 3,0 & 3,5 & 3,0 \\
\hline 56 & $28 / 08 / 80$ & 29,3 & 2,5 & 29,5 & 40,0 \\
\hline 63 & $04 / 09 / 80$ & 27,5 & 3,5 & 50,5 & 63,0 \\
\hline 71 & $12 / 09 / 80$ & 23,5 & 9,5 & 70,5 & 88,0 \\
\hline 78 & $19 / 09 / 80$ & 33,5 & 6,0 & 53,0 & 71,0 \\
\hline 85 & $26 / 09 / 80$ & 23,0 & 7,5 & 2,5 & 115,0 \\
\hline 91 & $02 / 10 / 80$ & 10,5 & 4,5 & 6,0 & 27,0 \\
\hline 98 & $09 / 10 / 80$ & 12,3 & 6,0 & 13,0 & 203,0 \\
\hline 105 & $16 / 10 / 80$ & 7,5 & 12,5 & 44,5 & 329,0 \\
\hline 112 & $23 / 10 / 80$ & 10,3 & 14,0 & 36,5 & 449,0 \\
\hline 119 & $30 / 10 / 80$ & 12,3 & 46,5 & 34,5 & 553,0 \\
\hline 126 & $06 / 11 / 80$ & 7,3 & 26,5 & 29,0 & 158,0 \\
\hline 133 & $13 / 11 / 80$ & 15,5 & 21,5 & 49,5 & 258,0 \\
\hline 140 & $20 / 11 / 80$ & 6,0 & 4,0 & 18,5 & 70,0 \\
\hline 147 & $27 / 11 / 80$ & 11,0 & 14,0 & 51,0 & 54,0 \\
\hline 161 & $11 / 12 / 80$ & 36,0 & 64,5 & 35,0 & 17,0 \\
\hline 168 & $18 / 12 / 80$ & 14,5 & 16,5 & 6,5 & 21,0 \\
\hline 173 & $23 / 12 / 80$ & 5,8 & 37,5 & 4,5 & 5,0 \\
\hline 180 & $30 / 12 / 80$ & 6,8 & 15,0 & 6,0 & 0,0 \\
\hline 189 & $08 / 01 / 81$ & 17,5 & 9,0 & 5,0 & 0,0 \\
\hline 210 & $29 / 01 / 81$ & 5,0 & 6,0 & 4,0 & 0,0 \\
\hline 217 & $05 / 02 / 81$ & 1,3 & 0,0 & 1,0 & 0,0 \\
\hline 225 & $13 / 02 / 81$ & 0,8 & 0,5 & 0,5 & 0,0 \\
\hline 231 & $19 / 02 / 81$ & 1,0 & 0,0 & 0,5 & 0,0 \\
\hline 239 & $27 / 02 / 81$ & 0,5 & 0,0 & 0,0 & 0,0 \\
\hline 245 & $05 / 03 / 81$ & 0,0 & 0,0 & 0,0 & 0,0 \\
\hline 253 & $13 / 03 / 81$ & 0,5 & 0,0 & 0,0 & 0,0 \\
\hline
\end{tabular}


APÊNDICE 6 - Nümero médio de machos coletados por armadilha e por varie dade, no período de 11/06/81 a 01/04/82 (Pomar B - 2o ano).

\begin{tabular}{|c|c|c|c|c|c|}
\hline \multirow{2}{*}{$\begin{array}{c}\text { Dias } \\
\text { acumulados }\end{array}$} & \multirow{2}{*}{ Data } & \multicolumn{4}{|c|}{ Variedade } \\
\hline & & Pêra & Piralima & Cravo & Murcote \\
\hline 7 & $11 / 06 / 81$ & 0,3 & 0,0 & 0,0 & 1,0 \\
\hline 14 & $25 / 06 / 81$ & 8,5 & 0,0 & 0,0 & 6,0 \\
\hline 21 & $02 / 07 / 81$ & 11,8 & 1,0 & 3,5 & 11,0 \\
\hline 28 & $09 / 07 / 81$ & 12,3 & 0,5 & 4,0 & 3,0 \\
\hline 35 & $16 / 07 / 81$ & 9,8 & 1,0 & 17,0 & 7,0 \\
\hline 43 & $24 / 07 / 81$ & 12,0 & 4,0 & 18,5 & 20,0 \\
\hline 49 & $30 / 07 / 81$ & 8,0 & 2,5 & 34,5 & 20,0 \\
\hline 56 & $06 / 08 / 81$ & 6,5 & 2,0 & 26,5 & 15,0 \\
\hline 63 & $13 / 08 / 81$ & 9,5 & 7,0 & 31,0 & 15,0 \\
\hline 70 & $20 / 08 / 81$ & 8,5 & 3,5 & 39,0 & 22,0 \\
\hline 77 & $27 / 08 / 81$ & 10,3 & 9,5 & 134,5 & 30,0 \\
\hline 84 & $03 / 09 / 81$ & 34,3 & 14,5 & 272,5 & 90,0 \\
\hline 91 & $10 / 09 / 81$ & 63,3 & 49,5 & 493,5 & 24,0 \\
\hline 98 & $17 / 09 / 81$ & 69,3 & 59,5 & 274,0 & 41,0 \\
\hline 103 & $22 / 09 / 81$ & 48,0 & 44,5 & 104,5 & 75,0 \\
\hline 112 & $01 / 10 / 81$ & 65,3 & 88,5 & 185,0 & 131,0 \\
\hline 119 & $08 / 10 / 81$ & 50,3 & 33,5 & 48,5 & 95,0 \\
\hline 126 & $15 / 10 / 81$ & 43,0 & 28,5 & 58,0 & 419,0 \\
\hline 134 & $23 / 10 / 81$ & 86,3 & 53,0 & 63,5 & 648,0 \\
\hline 140 & $29 / 10 / 81$ & 31,8 & 22,0 & 37,0 & 215,0 \\
\hline 147 & $05 / 11 / 81$ & 53,5 & 28,0 & 61,0 & 372,0 \\
\hline 154 & $12 / 11(81$ & 61,0 & 13,5 & 81,0 & 210,0 \\
\hline 168 & $26 / 11 / 81$ & 136,0 & 58,5 & 308,0 & 688,0 \\
\hline 175 & $03 / 12 / 81$ & 55,0 & 31,0 & 155,0 & 188,0 \\
\hline 182 & $10 / 12 / 81$ & 61,5 & 16,0 & 84,5 & 110,0 \\
\hline 189 & $17 / 12 / 81$ & 57,0 & 12,0 & 87,5 & 84,0 \\
\hline 194 & $22 / 12 / 81$ & 47,8 & 6,0 & 110,5 & 3,0 \\
\hline 202 & $30 / 12 / 81$ & 85,3 & 8,0 & 71,0 & 4,0 \\
\hline 210 & $07 / 01 / 82$ & 72,3 & 3,5 & 20,0 & 2,0 \\
\hline 217 & $14 / 01 / 82$ & 37,5 & 5,0 & 10,0 & 1,0 \\
\hline 224 & $21 / 01 / 82$ & 11,0 & 0,0 & 1,0 & 0,0 \\
\hline 231 & $28 / 01 / 82$ & 8,0 & 0,5 & 0,5 & 1,0 \\
\hline 238 & $04 / 02 / 82$ & 7,8 & 0,5 & 0,0 & 0,0 \\
\hline 245 & $11 / 02 / 82$ & 12,8 & 0,0 & 0,0 & 0,0 \\
\hline 252 & $18 / 02 / 82$ & 0,0 & 0,0 & 0,0 & 0,0 \\
\hline 260 & $26 / 02 / 82$ & 2,5 & 0,0 & 0,0 & 0,0 \\
\hline 266 & $04 / 03 / 82$ & 1,5 & 0,0 & 0,0 & 0,0 \\
\hline 273 & $11 / 03 / 82$ & 0,5 & 0,0 & 0,0 & 0,0 \\
\hline 280 & $18 / 03 / 82$ & - & 0,0 & 0,0 & 0,0 \\
\hline 287 & $25 / 03 / 82$ & 0,5 & 0,0 & 0,0 & 0,0 \\
\hline 294 & $01 / 04 / 82$ & 0,3 & 0,0 & 0,0 & 0,0 \\
\hline
\end{tabular}


APÊNDICE 7 - Nümero mëdio de machos coletados por armadilha e por varie dade, no período de 08/07/82 a 02/12/82 (Pomar B - 30 ano).

\begin{tabular}{cccccc}
\hline \multirow{2}{*}{$\begin{array}{c}\text { Dias } \\
\text { acumulados }\end{array}$} & Data & \multicolumn{4}{c}{ Variedade } \\
\cline { 3 - 5 } & & Pêra & Piralima & Cravo & Murcote \\
\hline 7 & $08 / 07 / 82$ & 0,5 & 0,0 & 0,5 & 2,0 \\
14 & $15 / 07 / 82$ & 1,5 & 0,0 & 0,5 & 2,0 \\
21 & $22 / 07 / 82$ & 1,5 & 0,0 & 0,0 & 1,0 \\
27 & $28 / 07 / 82$ & 1,3 & 0,0 & 0,5 & 0,0 \\
34 & $05 / 08 / 82$ & 2,5 & 1,0 & 1,0 & 3,0 \\
41 & $12 / 08 / 82$ & 4,0 & 0,5 & 0,0 & 2,0 \\
48 & $19 / 08 / 82$ & 0,8 & 0,5 & 0,0 & 3,0 \\
55 & $26 / 08 / 82$ & 2,3 & 1,0 & 0,5 & 2,0 \\
62 & $02 / 09 / 82$ & 1,5 & 0,0 & 0,5 & 4,0 \\
69 & $09 / 09 / 82$ & 1,0 & 0,0 & 0,5 & 0,0 \\
76 & $16 / 09 / 82$ & 1,0 & 0,5 & 0,0 & 2,0 \\
83 & $23 / 09 / 82$ & 2,0 & 0,5 & 0,0 & 9,0 \\
90 & $30 / 09 / 82$ & 2,5 & 0,0 & 0,5 & 0,0 \\
104 & $14 / 10 / 82$ & 1,0 & 0,5 & 5,5 & 19,0 \\
111 & $21 / 10 / 82$ & - & - & - & - \\
119 & $29 / 10 / 82$ & 3,3 & 0,0 & 5,0 & 19,0 \\
125 & $04 / 11 / 82$ & 0,8 & 0,0 & 0,5 & 5,0 \\
133 & $12 / 11 / 82$ & 4,3 & 0,0 & 0,0 & 3,0 \\
139 & $18 / 11 / 82$ & 0,5 & 0,0 & 0,0 & 1,0 \\
146 & $25 / 11 / 82$ & 0,0 & 0,0 & 0,0 & 3,0 \\
153 & $02 / 12 / 82$ & 0,0 & 0,0 & 0,0 & 1,0 \\
\hline
\end{tabular}


APÊNDICE 8 - Número médio de machos coletados por armadilha e por varie dade, no período de 14/07/83 a 02/12/83 (Pomar B - 40 ano).

\begin{tabular}{cccccr}
\hline \multirow{2}{*}{$\begin{array}{c}\text { Dias } \\
\text { acumulados }\end{array}$} & Data & \multicolumn{4}{c}{ Variedade } \\
\cline { 3 - 5 } & & Pêra & Pira1ima & Cravo & Murcote \\
\hline 28 & $14 / 07 / 83$ & 2,3 & 0,0 & 0,0 & 6,0 \\
42 & $28 / 07 / 83$ & 0,0 & 0,5 & 1,5 & 10,0 \\
63 & $18 / 08 / 83$ & 1,0 & 0,0 & 1,0 & 6,0 \\
76 & $01 / 09 / 83$ & 4,0 & 2,5 & 2,0 & 6,0 \\
97 & $22 / 09 / 83$ & 6,0 & 0,5 & 8,0 & 33,0 \\
111 & $06 / 10 / 83$ & 2,0 & 5,5 & 8,0 & 2,0 \\
125 & $20 / 10 / 83$ & 2,8 & 7,0 & 22,5 & 11,0 \\
139 & $03 / 11 / 83$ & 1,5 & 3,0 & 11,0 & 0,0 \\
154 & $18 / 11 / 83$ & 4,8 & 12,0 & 15,5 & 4,0 \\
168 & $02 / 12 / 83$ & 2,3 & 7,5 & 4,0 & 2,0 \\
\hline
\end{tabular}

